Finance and Economics Discussion Series Divisions of Research \& Statistics and Monetary Affairs Federal Reserve Board, Washington, D.C.

\title{
Expectations Formation and the Effectiveness of Strategies for Limiting the Consequences of the Zero Bound on Interest Rates
}

\section{David L. Reifschneider and John M. Roberts}

2005-70

NOTE: Staff working papers in the Finance and Economics Discussion Series (FEDS) are preliminary materials circulated to stimulate discussion and critical comment. The analysis and conclusions set forth are those of the authors and do not indicate concurrence by other members of the research staff or the Board of Governors. References in publications to the Finance and Economics Discussion Series (other than acknowledgement) should be cleared with the author(s) to protect the tentative character of these papers. 


\title{
Expectations Formation and the Effectiveness of Strategies For Limiting the Consequences of the Zero Bound on Interest Rates
}

\author{
by \\ David L. Reifschneider and John M. Roberts* \\ First version: \\ August 2004 \\ Current version: \\ December 12, 2005
}

\begin{abstract}
We use simulations of the Federal Reserve's FRB/US model to examine the efficacy of a number of proposals for reducing the consequences of the zero bound on nominal interest rates. Among the proposals are: a more aggressive monetary policy; promises to make up any shortfall in monetary ease during the zero-bound period by keeping interest rates lower in the future; and the adoption of a price-level target. We consider two assumptions about expectations formation. One assumption is fully modelconsistent expectations (MCE) - a reasonable assumption when a policy has been in place for some time, but perhaps less so for a newly announced policy. We therefore also consider the possibility that only financial markets have MCE, and that other agents form their expectations using a small-scale VAR model estimated using historical data. All of the policies noted above are highly effective at reducing the adverse effects of the zero bound under MCE, but their efficacy drops considerably when households and firms base their expectations on the historical average behavior of the economy, and only investors fully recognize the economic implications of the various proposals.
\end{abstract}

* Communicating author. Address: Mail Stop 61, Board of Governors of the Federal Reserve System, Washington DC 20551. Email: john.m.roberts@ffrb.gov. The views presented in this paper are those of the authors and do not necessarily represent those of the Federal Reserve Board or its staff. We are grateful to Anil Kashyap, Takeo Hoshi, and other participants at the NBER/CIRJE/EIJS/CEPR Japan Project conference (September 1-2, 2004) for helpful comments. 
In this paper, we explore the effectiveness of a number of recent proposals for reducing the consequences of the zero lower bound on interest rates using simulations of the Federal Reserve's FRB/US model. Our focus is on strategies that alter expectations of future monetary policy when current interest rates are pinned at zero; such policies have been discussed by, among others, Krugman (1998), Reifschneider and Williams (2000), Svensson (2000), Yates (2002), and Eggertson and Woodford (2003). Some of these studies examined the effects of changes in monetary policy using stylized models-for example, Eggertson and Woodford (2003). We believe that using a model such as $\mathrm{FRB} / \mathrm{US}$ has advantages relative to these other models because in FRB/US a much richer range of economic mechanisms is at work, and these additional mechanisms can point to drawbacks and advantages of certain policies. Moreover, the FRB/US model is estimated, and thus may provide a more realistic platform for policy evaluation.

In particular, we use the FRB/US model to explore the implications of alternative expectations-formation mechanisms for financial market participants that differ from those used by firms and households. Many of the proposals for dealing with the zero bound rely on influencing expectations, both of future interest rates and of future inflation. While recent experience suggests that financial markets may quickly understand and react to a shift in monetary policy, we think it is less likely that firms and households will respond immediately. We therefore make two alternative assumptions about expectations. In the first case, all agents fully understand the working of the economy and how policy will be implemented under the zero bound. In our view, this would be a reasonable assumption when a policy has been in place for some time. In the second case, financial markets fully understand how policy will operate and change their expectations accordingly, but firms and households continue to assume that policy will be set as in the past, and thus form their expectations in line with the average historical behavior of the economy. We show that the degree of understanding of those outside of financial markets matters a great deal to the efficacy of many of the proposed remedies.

One reason the zero bound on interest rates is a concern is that central banks typically respond to weak aggregate demand conditions by lowering short-term interest rates. This response - coupled with the expectation that short-term rates will remain low until the economy recovers - leads to a fall in long-term bond rates that helps to stimulate aggregate demand. But of course, once the nominal short-term interest rate reaches zero, central banks cannot provide any further immediate stimulus through this channel. 
Central bank policy can, however, continue to influence expectations of future short-term interest rates, at least for dates far enough in the future that the zero bound is not expected to constrain policy. Such influence may be the result of central bank statements about future plans for interest rate setting or may come through private agents' expectations based on historical experience of central bank behavior. Under the expectations hypothesis of the term structure, any such influence will affect real bond rates today, thereby stimulating the economy.

In our analysis, we consider a number of specific proposals to mitigate the effects of the zero bound:

- Reifschneider and Williams (2000) argue that adopting a monetary policy that is more aggressive can reduce the adverse effects of the zero bound. We model this more-aggressive policy as larger coefficients on inflation and output in a Taylor rule.

- A central bank may promise to make up any shortfall in short-term nominal interest rates relative to the Taylor rule that occurs during a zero-bound period (Reifschneider and Williams, 2000). Under such a policy, future short-term interest rates will be lower than they would be under the Taylor rule, and, in particular, will stay at zero for a more extended period.

- Krugman (1998) has proposed raising the central bank's inflation target permanently (or at least for a very long period) as a way of escaping a zero-bound episode. To illustrate this strategy, we evaluate the effects of announcing a permanent shift in the inflation target incorporated into the standard Taylor rule.

- Reifschneider and Williams also proposed mitigating the effects of the zero lower bound by implementing a policy that quickly reduces the short-term interest rate whenever hitting the zero bound is imminent. We implement this proposal by deviating from the standard Taylor rule and immediately setting the funds rate to zero following the onset of a large contractionary shock to the economy.

- A more-radical departure from the Taylor rule would be to replace its inflation-target component with a price-level target. Such a policy has been advocated by Wolman (2005) and Eggertson and Woodford (2003), among others.

- Finally, we consider the adoption of rules that link the change in the short-term interest rate to deviations of inflation and the output gap from their target levels. Such rules have been advocated by Levin, Wieland, and Williams (2003). 
We evaluate these various policies by looking at the response of the economy to a specific shock. In particular, we examine the effects of each policy in response to a disturbance to aggregate spending that, under a baseline Taylor rule policy, would pin the short-term interest rate at zero for a period of four to five years. This deterministic approach allows us to examine closely the economic mechanisms at work under the different monetary policies and expectational assumptions. We believe it to be a useful complement to other work such as Reifschneider and Williams (2000), Coenen, Orphanides, and Wieland (2004), and Wolman (2005), in which stochastic simulations are used to give some sense of the average performance of various policy alternatives under the full range of disturbances that can hit the economy.

In this paper, we focus on monetary policies that involve altering interest-rate expectations. However, there have been other suggestions for dealing with the zero bound. By and large, these alternative approaches involve exploiting liquidity or portfolio-balance channels to influence long-term interest rates or the exchange rate (see, for example, Clouse et al., 2000, and Bernanke et al., 2004). Because there is little firm evidence that such channels are quantitatively important at the aggregate level, they are not built into the structure of the FRB/US model. Accordingly, we are not well-placed to evaluate the potential efficacy of these proposals, and so do not discuss them here.

We limit ourselves to monetary policies that are similar in spirit to the well-known Taylor rule. In particular, we do not consider policies that have been chosen to optimize a particular social welfare function conditional on a specific representation of the structure of the economy. One reason for focusing on Taylor-type rules rather than optimized policies is the finding of Levin, Wieland, and Williams $(1999,2003)$ and Taylor (1999) that rules optimized for one model may perform quite poorly in other models. Given the considerable uncertainty about the true structure of the economy, a central bank would thus be ill-advised to choose a policy optimized for any particular model. By contrast, Taylor-type rules appear to provide at least adequate macroeconomic performance in a broad range of models (Taylor, 1999). In addition, a number of studies - such as Clarida, Gali, and Gertler (2000) and English, Nelson, and Sack (2003) - have argued that Taylor-type rules are a good approximation to actual central bank behavior.

We also consider the role fiscal policy might play in addressing the problems related to the zero bound. Fiscal policy is, of course, always an option when short-term interest rates are pinned at zero. Furthermore, fiscal policy may be particularly effective at the 
zero bound, because the rise in bond rates and resultant crowding out that ordinarily accompany fiscal stimulus are less of a factor when the economy is abnormally weak. We confirm this intuition with simulations of the FRB/US model.

The paper is organized as follows: Section 1 presents background information on the FRB/US model and the baseline simulations. Section 2 considers the implications of the various policy rules under fully rational, model-consistent expectations. Section 3 considers the sensitivity of the results to alternative assumptions about inflation expectations. Section 4 presents our results on fiscal policy and section 5, our conclusions.

\section{Background and baseline simulations}

\subsection{The FRB/US model}

We use the Federal Reserve Board's FRB/US model for our analysis. FRB/US is described in detail in Brayton and Tinsley (1996). ${ }^{1}$ For the present discussion, some important features of FRB/US are:

- The main behavioral relationships in FRB/US are derived from explicit optimization problems, under the assumption that the adjustment of many factors (including consumption, investment, employment, prices, and wages) is costly. These frictions imply that the economy adjusts only gradually to shocks.

- Most behavioral relationships in FRB/US are estimated. In particular, considerable care has been taken to ensure that the key correlations among variables observed in the U.S. data—including persistence - are matched.

- In financial markets, standard asset-valuation formulas are used. In particular, longterm interest rates are a weighted average of expected future short-term interest rates, plus a risk premium that is modeled as serially correlated and related to the expected cyclical state of the economy; the value of corporate equity is equal to the present discounted value of expected dividends; and the real exchange rate is determined by an open-interest parity condition.

1. Additional information about the FRB/US model is provided in Brayton, Mauskopf, Reifschneider, Tinsley and Williams (1997); Brayton, Levin, Tryon, and Williams (1997); and Reifschneider, Tetlow, and Williams (1999). Full documentation on the model's equations and coefficients is available from the authors on request. 
- Explicit expectational variables also play important roles in the model's nonfinancial sectors; examples include the dependence of consumption and residential investment on permanent household income; and the dependence of business investment on expected future sales as well as the expected evolution of the cost of capital.

- Inflation is modeled using a variant of the New Keynesian Phillips curve. In this specification (which encompasses the behavior of both wages and prices), inflation depends on expected future inflation and past actual inflation, as well as expected resource utilization and the markup of prices over trend unit labor costs.

We initially consider simulations in which expectations are fully model consistent (or "rational"). In particular, in section 2, we assume that when monetary policy changes, expectations formation - and thus the dynamics of the economy — change accordingly. In section 4 , we relax this assumption.

As noted above, the monetary-policy strategies we analyze implicitly operate by promising to keep real future short-term interest rates lower than they otherwise would be; under the expectations hypothesis of the term structure, such a promise, if deemed credible by the public, will lower real long-term interest rates today. These strategies work because in FRB/US, as in many other macroeconomic models, current real longterm interest rates, operating through the cost of capital, have important direct effects on current spending; movements in real long-term rates also indirectly affect real activity and inflation in the model through their influence on other asset prices, including stock market valuations and the real exchange rate. Of course, future real short-term rates are the difference between expected nominal rates and expected inflation, and so monetary policy can work on both of these components: Policy can try to lower expectations of future nominal short-term rates even though current rates are pinned at zero, and the central bank can attempt to raise inflation expectations by promising a relatively easy policy in the future.

We have chosen a version of the Taylor rule as our baseline monetary policy (see Taylor 1999): ${ }^{2}$

$$
r_{t}=\max \left[r^{*}+\pi_{t}+\alpha\left(\pi_{t}-\pi_{t}^{*}\right)+\beta \operatorname{gap}_{t}, 0\right]
$$

where $r_{t}$ is the short-term policy rate (specifically, the federal funds rate); $r^{*}$ is the 
equilibrium real interest rate; $\pi_{t}$ is inflation, here defined to be the lagging four-quarter percent change in the core PCE price index; and gap is the output gap, defined to be the percent deviation of GDP from an estimate of its trend or potential level. In the revised Taylor rule, $\alpha=0.5$ and $\beta=1.0$. (In Taylor's original specification, $\alpha=0.5$ and $\beta=0.5$.) Taylor (1999) argues that the revised rule has been a good representation of U.S. monetary policy since the mid-1980s. In addition, Taylor and others have found that this rule does at least an adequate job of stabilizing the U.S. economy, based on simulations of a broad range of models. ${ }^{3}$

\subsection{The baseline shock}

We begin by evaluating the comparative macroeconomic performance of different monetary policies in the face of an aggregate demand shock so severe that nominal shortterm interest rates are pinned at zero for several years. The particular disturbance is a large, adverse hit to household spending that initially is equal to almost $1 \frac{1}{2}$ percent of aggregate consumption; the underlying innovation to household demand is assumed to fade away linearly over the next six years. However, because households and firms respond only gradually to changes in fundamental conditions in the model, the shock yields a steady decline in the actual levels of aggregate consumption and output during the first two or three years of the zero bound episode; thereafter, real activity recovers only slowly as the underlying disturbance continues to fade away. In the base case, all agents are assumed to have model-consistent expectations and to know the duration of the shock once it arrives.

Figure 1 shows the effect of the shock both with and without the imposition of the zero lower bound on nominal interest rates. When the zero bound is not imposed, the funds rate falls to almost -2 percent, reaching a trough after three years. Under this (unattainable) monetary policy response, the output gap widens to $2 \frac{1}{2}$ percent at its trough and inflation falls to $-1 / 2$ percent, two percentage points below baseline. The zero bound exacerbates the recession considerably: With monetary policy constrained for about five years, the output gap widens even further, to 4 percent below potential at the

2. We discuss our fiscal policy assumptions in section 4 .

3. Some have argued that a more-realistic representation of U.S. monetary policy in recent years would incorporate the lagged funds rate in addition to the output and inflation gaps. For example, Clarida, Gali, and Gertler (2000) find a coefficient of 0.8 on the lagged funds rate and English, Nelson, and Sack (2003) find a coefficient of 0.7 . We experimented with such a specification and found that, for present purposes, it made little difference for our conclusions. 
trough. However, the severity of the deflation that results is only moderately worse than that which occurs in the absence of the zero lower bound; at the trough, consumer prices are falling 1 percent year, only $1 / 2$ percentage point more than in the unconstrained case. In part, this modest worsening occurs because inflation has a relatively low sensitivity to economic slack in the model. In addition, the longer-run outlook for inflation is roughly the same under the two cases, implying similar long-term expectational effects in both simulations. Whether or not the zero bound is imposed, financial market participants push the yield on ten-year Treasury bonds down sharply immediately after the shock hits the economy. ${ }^{4}$ However, long-term rates fall about $1 / 2$ percentage point less when the zero bound is imposed, consistent with agents' expectations for the future course of short-term interest rates.

\subsection{Loss estimates}

To provide a convenient metric for comparing the performance of different policies, we compute a loss over the first ten years following the shock. The loss is computed as the sum of two components - squared deviations of the output gap from zero and (annualized) inflation from its target - equally weighted and cumulated over forty quarters, as follows:

$$
L=\sum_{\mathrm{t}=0,40}\left[\operatorname{gap}_{t}^{2}+\left(\pi_{t}-\pi^{*}\right)^{2}\right] .
$$

The specification of this loss function is intended for illustrative purposes only and does not necessarily bear any particular relationship to actual policymaker preferences. That said, we see this loss function as a reasonable way to summarize the comparative performance of different rules, given that its arguments are broadly consistent with the Federal Reserve's dual mandate to stabilize prices and to keep the economy expanding at its maximum sustainable rate.

Table 1 reports ten-year losses under alternative monetary policies, with and without the imposition of the zero lower bound constraint in simulation; line 1 shows the loss under the standard Taylor rule. The cost imposed by the zero bound is substantial in this case,

4. We also examined the implications of gradual learning about the duration of the shock. In this case, bond rates decline more slowly and thus provide less upfront support to aggregate demand. However, the output gap still widens by roughly as much as it does under instantaneous recognition because agents do not immediately perceive the full extent of the future loss in income and so they initially reduce their spending by less. 
with the constrained loss being almost twice as great (1.94) as what could theoretically be attained if nominal interest rates were free to fall below zero. This result confirms previous research indicating that the zero lower bound may lead to a serious degradation in economic performance if monetary policy follows the Taylor rule.

\section{Implications of alternative policy rules under model-consistent expectations}

In this section, we consider the effects of various alternatives to the baseline monetary policy.

\subsection{More aggressive Taylor rule}

The first set of alternative policies maintains the general structure of the Taylor rule of equation 1 but uses different parameters. In particular, we consider more aggressive parameters on both output and inflation, along the lines suggested by Henderson and McKibbin (1993). In the first case, we raise the coefficient on inflation, $\alpha$, from 0.5 to 2.0 and then re-simulate the effects of the large demand shock. In the second case, we maintain the higher coefficient on inflation and in addition raise the coefficient on the output gap, $\beta$, from 1.0 to 2.0 .

As can be seen in figure 1, a more aggressive Taylor rule greatly mitigates the adverse effects of the demand shock. In the policy represented by the dotted line, only the coefficient on inflation is increased, and this change alone shrinks the loss in output to that generated under the unconstrained standard Taylor rule, our benchmark policy. Importantly, this diminution occurs despite higher nominal bond yields because the aggressive policy more effectively checks the decline in inflation; this effect in turn implies a larger fall in real bond rates and therefore more economic stimulus. The root cause of the smaller inflation effect is the public's belief that the central bank, once unconstrained, will aggressively seek to bring inflation back to its target rate. Because current inflation depends on expected future inflation, the more-aggressive policy thus boosts inflation even when interest rates are constrained at zero.

In the simulation represented by the dash-dot line, the coefficient on output in the Taylor rule is also boosted, from 1.0 to 2.0. As a result, the federal funds rate falls to zero a shade more quickly and remains there a little longer. However, overall macroeconomic performance in this case is little different from that which occurs when only the inflation parameter is boosted. 
Lines 2 and 3 of table 1 report the implications of these more-aggressive strategies for the ten-year loss. As shown in the column headed "relative performance", both policies reduce the loss below the benchmark level obtained under the unconstrained standard Taylor rule. Hence, these results suggest that, in the event of a downturn so severe it produces a zero-bound episode, a central bank could replicate or surpass the economic performance obtainable under the benchmark policy by announcing a strategy of always reacting vigorously to undesirable movements in inflation when free to do so. And in fact, evidence presented by Reifschneider and Williams suggests that such policies would be a good strategy to follow at all times because they appear to perform better in response to a broad range of disturbances at any target inflation rate above zero. Nonetheless, the zero lower bound limits the effectiveness of these strategies as well: As shown in the column headed "Cost of the ZLB", the imposition of the zero bound more than doubles, and in one case almost triples, the loss generated under these two policies.

One potential advantage of an aggressive Taylor rule is that a central bank could implement it under normal conditions when the zero lower bound does not constrain conventional open-market operations. Policymakers would thus be able to establish a reputation for responding aggressively to movements in inflation, which they will be expected to do once they are free to do so. As we noted in the introduction, it is likely that, outside of financial markets, agents learn only gradually how monetary policy affects inflation by observing the actual workings of the economy over time; perhaps in contrast to financial analysts, they do not learn by working through the implications of a newly announced policy in the context of some mental economic model. As we discuss in section 3, if expectations formation among some agents does not adjust immediately to a newly-announced policy, but instead continues to be based on the average historical behavior of the funds rates and the overall economy, the benefits of the announced change in policy may be substantially diminished.

\subsection{Make-up rules}

We next consider a policy in which the central bank pledges to "make up" at a later date any shortfall in the interest rate that occurs when nominal interest rates are constrained at zero. As in Reifschneider and Williams (2000), we specify this "R-W" policy as:

$$
r_{t}=\max \left[r^{*}+\pi_{t}+0.5\left(\pi_{t}-\pi_{t}^{*}\right)+1.0 \operatorname{gap}_{t}-\gamma Z_{t}, 0\right],
$$


where $Z$ is the cumulated past deviations of the short-term interest rate from the prescriptions of the standard Taylor rule. In our simulations, we use $\gamma=0.5$.

The dotted line in figure 2 shows the implications of the R-W policy. As can be seen, the full make-up policy prolongs the period that the nominal federal funds rate stays at zero by over a year, and subsequently keeps it at a comparatively low level for an additional half-year. This additional easing, after taking into account its effects on inflation, translates into a substantially lower average level of the real funds rate over the first ten years. Thus, real expected bond yields fall by almost as much as in the absence of the zero-bound constraint. For this reason, the policy is quite effective at mitigating the loss in aggregate production associated with the demand shock. In particular, the trough in the output gap is only slightly deeper than when the zero bound is not imposed, and the subsequent rebound in real activity is more pronounced. Less economic slack in turn limits the downward pressure on inflation, thereby shortening the period of outright deflation to only three years. Overall, macroeconomic performance under the R-W rule is similar to that obtained under the standard Taylor rule in the absence of the zero-bound constraint (table 1, line 4).

Once sufficient time has passed, monetary policy under the R-W policy reverts to what it would have been under the Taylor rule. This return to normalcy would be an advantage for a central bank that prefers a Taylor rule most of the time, and only wants to deviate from such a policy in exceptional circumstances. But a corresponding disadvantage is that a central bank would not be able to establish a reputation prior to the advent of a zero-bound episode of making-up past shortfalls. Hence, the efficacy of this policy would depend heavily on the ability of the central bank, once the zero bound on nominal interest rates has been reached, both to explain the new policy's macroeconomic implications to the public, and to convince people that it will follow through on its promises.

\subsection{Giving up too soon}

The dash-dot line in figure 2 illustrates the consequences if the central bank abandons the R-W policy before past funds rate shortfalls are completely made up. The motivation behind this scenario is that a central bank may prefer the standard Taylor rule and, once the economy has largely recovered, would be tempted to revert quickly to its preferred policy despite its earlier promise. We assume that private-sector agents correctly 
anticipate that the central bank will abandon its announced policy prematurely; in short, we assume that the central bank does not enjoy complete credibility.

In this simulation, the central bank begins to raise the nominal funds rate two quarters earlier than in the full make-up case, and brings it back in line with the prescriptions of the standard Taylor rule by the end of the seventh year. At that point, the output gap has recovered more than 85 percent of the loss incurred at the trough and inflation is back above $1 / 4$ percent. Under these conditions, policymakers might conceivably be tempted to revert to their normal operating procedure. But as can be seen in line 5 of table 1 , an early reversion - if anticipated by the public - undoes much of the benefit of the make-up strategy. The difference is surprisingly large, given that the central bank ends up raising rates just a couple of quarters earlier, and to similar levels. The reason for this large difference is that any alteration in monetary policy that lowers inflation further will, by increasing real bond rates, lead to a fall in output that feeds back and weakens inflation further. This potential drawback of the R-W policy applies more generally: The effectiveness of any strategy based on anticipated future policy actions will be greatly diminished if the announced change in policy is not deemed fully credible by the public.

\subsection{Pre-emptive policy and a permanently higher inflation target}

We next consider two other policies that are relatively modest departures from the Taylor rule (figure 3). Both strategies involve deviating from the baseline rule immediately following the onset of the shock, the first by immediately reducing the funds rate to zero (the dash-dotted line), and the second by announcing a permanent increase in the longrun inflation target (the dotted line). As can be seen, the preemptive policy has essentially no effect on either output or inflation, in part because the quicker drive to zero has only a marginal and fleeting impact on nominal long-term yields. Moreover, because inflation is inertial in FRB/US, pre-emption has little effect on inflation expectations. ${ }^{5}$

In the other modification to the Taylor rule, the central bank announces a permanent increase in the inflation target of 1 percentage point, to 2.5 percent, immediately

5. While the pre-emptive strategy of driving directly to zero has only modest effects in this specific simulation, unpublished work involving stochastic simulations of the FRB/US model suggests that a policy of moving rapidly to the zero bound when aggregate demand markedly weakens does reduce the frequency and average severity of zero-bound episodes. 
following the onset of the demand shock. ${ }^{6}$ In the simulation, households, firms, and investors are all assumed to view the announced change in policy as fully credible. Because inflation is inertial, such an objective can be achieved only by keeping real interest rates lower for a time than they otherwise would be, in order to generate the increase in real activity required to push up inflation. Agents, understanding this process, mark down their expectations for the average level of the real funds rate in the future. This revision in expectations leads to a larger decline in the real bond rate than occurs under the benchmark monetary policy. Nominal bond yields, by comparison, fall by less than under the baseline policy because of the higher level of expected inflation.

Although the announcement of a higher target leads to a fall in real bond rates that is roughly equivalent to what occurs under the Taylor rule without the zero bound constraint, this does not—-perhaps surprisingly_yield as mild a contraction in real activity (figure 3 ). ${ }^{7}$ There are two reasons for this result. First, the boost to inflation, because it is permanent and unanticipated, substantially erodes the real value of the existing stock of nominal government debt over time, and the resultant loss in wealth (actual and projected) damps consumption. Second, the higher long-run rate of inflation lowers the steady-state path of real corporate earnings because it increases the long-run interest-income share of nominal GDP, and so reduces real stock market wealth. While we suspect that the strength of these wealth effects may be unique to the FRB/US model, they nonetheless illustrate some of the adverse consequences that may result from permanently raising the inflation target.

Additional simulation results (not shown) suggest that a sufficiently large increase in the announced inflation target —on the order of four percentage points - would yield a loss in line with that produced by the standard Taylor rule without the zero bound constraint. However, we view this result as suggesting that an announced permanent increase in the inflation target is a poor way to address the problems created by the zero bound. First of all, if such a target was not deemed appropriate prior to the zero-bound episode, it is difficult to see why it should be afterwards - a consideration that would undercut the

6. Note that this exercise does not consider the efficacy of a general policy of maintaining a higher inflation target, and hence a higher average level of both inflation and nominal interest rates. Such a policy has been examined using stochastic simulations by - among others-Reifschneider and Williams (2000) and Coenen, Orphanides, and Wieland (2004).

7. Although loss estimates are presented in table 1 for this policy, their comparability to the other estimates is problematic because of an ambiguity concerning the appropriate inflation target to use in the loss calculation - should it be the baseline target used for all the other calculations ( $1 \frac{1 / 2}{2}$ percent), or the newly announced target of $2 \frac{1}{2}$ percent? We use the latter figure, both here and in line 6 of table 2 . 
credibility of the promised long-term change in policy, and so reduce its effectiveness. Second, other policies appear to perform better in mitigating the adverse effects of the zero lower bound while having only transitory effects on inflation. Finally, by its nature, this sort of conditional policy change is not one that the public could become familiar with beforehand and so incorporate into its expectational processes in advance of a zero bound episode.

\subsection{Price-level targeting and change rules}

We now consider policies that are more radical departures from the Taylor rule. One of these is a price-level targeting rule, in which inflation is dropped from the rule and replaced by the deviation of the price level from a target level:

$$
r_{t}=\max \left[\mathrm{r}^{*}+\pi_{t}+\varphi 100 \times\left(p_{t}-p^{*}\right)+\beta \operatorname{gap}_{t}, 0\right]
$$

where $p$ is the $\log$ of the price level and $p^{*}$ is the $\log$ of the target price level. We assume that the price-level target increases at the baseline target inflation rate of 1.5 percent. Under the price-level targeting rule, any shortfall in inflation during a period of weak aggregate demand will be made up later, thereby boosting expected inflation. In implementing this rule, we employ the same coefficient on the output gap as in the standard Taylor rule, $\beta=1.0$; for the coefficient on the price-level gap, we choose $\varphi=0.4$. This latter choice is motivated by the finding of Orphanides and Williams (2002) that this value is a robust choice across different models in a differenced version of the price-level rule. In addition, we find that this value leads to outcomes for the output gap that are similar to those obtained in the absence of the zero bound on nominal interest rates.

Equation 5 shows the other alternative we consider, a change rule similar in style to the Taylor rule except that the level of the nominal funds rate is replaced by its first difference:

$$
r_{t}-r_{t-1}=\alpha\left(\pi_{t}-\pi^{*}\right)+\beta g{ }_{t} .
$$

The change rule implies a high degree of serial correlation in short-term interest rates. Thus, as discussed in Levin, Wieland, and Williams (1999), it leads to larger movements in long-term interest rates for any given movement in short-term interest rates. Levin, Wieland, and Williams (2003) examined the performance of such change rules in five 
macroeconomic models, including FRB/US. Averaging over the performance in all five models, they concluded that values of $\alpha=0.4$ and $\beta=0.4$ were preferred. We find, however, that such a policy can lead to explosive behavior in versions of the FRB/US model in which expectations are based on historical relationships; we will discuss this issue in detail shortly. We therefore consider two different sets of parameters for the change rule - the values recommended by Levin, Wieland, and Williams, and values that imply a less aggressive (but more globally stable) policy response, $\alpha=0.1$ and $\beta=0.1$.

The dotted line in figure 4 shows the effects of adopting price level targeting. The period during which the funds rate is pinned at zero now lasts less than two years. As a consequence, the initial decline in the ten-year Treasury yield is much smaller. But more important, inflation is considerably higher under this policy than under the benchmark Taylor rule: Its low point is only $1 / 2$ percent and, as is to be expected under a policy in which a shortfall in the price level is eventually made up, inflation exceeds its long-run target starting in the seventh year of the simulation. But the excess in inflation relative to the desired long-run growth rate of the price level is quite mild - only $1 / 4$ percentage point on average over the second ten years of the simulation (not shown). And in the longer run inflation returns to its target level. As a consequence of the anticipated higher average level of inflation, real long-term interest rates fall more sharply than under the benchmark policy, stimulating real activity. In fact, under price-level targeting, the peak effect of the demand shock on the output gap is about the same as under the Taylor rule without the zero-bound constraint; moreover, output thereafter recovers a bit faster. Thus, this strategy appears capable of essentially undoing all the real-side effects of the zero bound.

As shown on line 8, column 4 of table 1, the ten-year loss under price-level targeting is about one half of that produced under the unconstrained Taylor rule policy. Moreover, the zero lower bound causes almost no deterioration in economic performance under this strategy, in that the loss with the constraint imposed is almost as small as the loss hypothetically attainable under price-level targeting if the funds rate were free to fall below zero. These results are perhaps not particularly surprising; the potential benefits of price-level targeting have been noted in a number of other papers, notably Svensson (1999) and Wolman (2005). This research finds that when expectations are forwardlooking and model consistent, as in these simulations with FRB/US, price-level targeting can yield superior outcomes to inflation targeting, even when the zero bound is not a consideration. 
The dash-dotted line in figure 4 shows the effects of the change rule described by equation 5 with the Levin-Wieland-Williams setting of the parameters $-\alpha=0.4$ and $\beta=0.4$. The initial shock now has a considerably milder effect on the output gap than under the unconstrained benchmark policy. This powerful result is an indication that this policy setting is particularly aggressive. However, as we will see in the next section, this policy leads to instabilities in FRB/US when expectations are not fully model-consistent, thus illustrating that policies that perform well in one model may not work so well in other models. That said, the simulation illustrates the potential for these types of strategies to offset the effects of the zero bound.

Under the change rule, the funds rate falls to zero more gradually than under the benchmark Taylor rule, and later rebounds more vigorously. Yet, because this nominal funds rate path is accompanied by almost no fall in inflation, the comparative decline in real short-term interest rates is much deeper. Thus, the real bond rate falls below 2 percent under this policy, as compared to roughly $23 / 4$ percent under the baseline policy, thereby providing the necessary offsetting stimulus to stabilize real output and inflation to a remarkable degree: As shown in table 1, line 9, the loss under this policy is only 9 percent of that incurred under the benchmark policy; moreover, a hypothetical change rule that was not constrained by the zero bound would bring only a small improvement in performance compared with the constrained rule.

The less aggressive change rule also performs remarkably well, at least under modelconsistent expectations (line 10, table 1). Although it generates a loss well above that produced by the more aggressive change rule (66.0 versus 17.2 ), its relative performance is still the second best of all the policies considered - 35 percent of the loss observed under the unconstrained benchmark policy. Moreover, the cost imposed by the zero lower bound is essentially nil under this strategy.

\section{How robust are these strategies to different expectational assumptions?}

So far, we have assumed that all agents in the economy change their methods for forming expectations in a model-consistent manner when the central bank announces a change in policy. There is some evidence that changes in monetary policy that have been in place for some time can affect inflation expectations throughout the economy. ${ }^{8}$ There is also

8. For example, two recent papers (Boivin and Giannoni, 2003, and Roberts, 2004) argue that the changes in monetary policy in the early 1980s can account for subsequent changes in inflation dynamics. 
some evidence that the beliefs of financial-market participants can respond rapidly to announced changes in monetary policy (Kohn and Sack, 2003, and Gürkaynak, Sack, and Swanson, 2005). However, we are not aware of any evidence that agents outside the financial sector are as quick to adjust their expectational processes to announced changes in monetary policy. Indeed, in many accounts of the disinflation of the early 1980s, a failure of inflation expectations to adjust quickly to the announced policy change in late 1979 played a crucial role in the ensuing recession (for example, Erceg and Levin, 2003).

In our view, the simulations we presented in the previous section can be viewed as reasonable approximations of the economy's dynamics under a monetary policy that has been in place for some time - thereby ensuring that all agents have had an opportunity to learn the implications of the particular policy. But we believe it is an open question whether the simulations provide as good a guide to the economy's behavior in the immediate aftermath of a newly announced, unfamiliar change in policy. Establishing that the policy regime has shifted may be especially difficult once the zero bound has been reached, precisely because one of the key ways a central bank typically signals its intentions - changing the short-term policy rate - can't be used. Of course, if a policy has been in place for some time, it is more reasonable to assume that expectations formation has adapted to the policy environment, and we believe it is this line of argument that justifies the use of model-consistent expectations in most of our simulation analysis.

To get a better notion of the importance of expectational assumptions for our results, we run the following experiment. We continue to assume that bond yields, equity prices, and the exchange rate are priced in a rational manner - that is, to assume that the expectations used in their pricing formulas are fully model-consistent. But we assume that expectations outside the financial sector more closely conform to predictions based on the average historical behavior of the economy.

Specifically, we generate expectations of future income, inflation, and other nonfinancial factors using the forecasts of an estimated small-scale VAR model. Under many conditions, the predictions from this small model are similar to those generated by the full-scale FRB/US model under model-consistent expectations (Brayton, Mauskopf, et al., 1997). But this similarity may break down in the circumstances considered here because the simulated zero-bound episode is so atypical from a historical perspective. For example, the VAR forecasts implicitly assume that the aggregate demand shock will be of typical duration when in fact it turns out to be unusually persistent. Moreover, the 
VAR forecasts do not impose the zero lower bound on the funds rate, implying that agents see the central bank as having more ability to stabilize the economy than it in fact does. Finally, the small-model forecasts are not derived using the actual monetary policy pursued by the central bank, but instead are based on the fixed estimated historical policy rule embedded in the VAR model.

Not surprisingly, the change in expectational assumptions has important implications for the dynamic response of the economy to the shock: As illustrated by the dotted line in figure 5, the zero lower bound is no longer a constraint on monetary policy. The milder response of both output and inflation under these conditions mostly reflects the combination of two factors - investors' recognition that the shock will be unusually persistent, and the failure of agents outside the financial sector to recognize this persistence. Because of the first factor, bond rates immediately drop following the onset of the shock, thereby supporting aggregate spending in a manner similar to what occurs under full model-consistent expectations. However, because households and firms do not recognize the full extent of the future decline in income and earnings implied by the shock, they cut back on spending by less than what occurs in the absence of expectational errors. The net effect of these two events is a much milder recession and a smaller initial decline in inflation. Nonetheless, there is eventually a more pronounced decline in inflation under VAR-based expectations because long-run inflation expectations outside the financial sector are less firmly anchored.

To evaluate the relative performance of different monetary policies under the alternative expectational assumption, we recalibrate the aggregate demand shock to yield a zerobound episode of approximately the same duration as that considered earlier. The recalibrated shock needs to be approximately 60 percent larger than before, assuming that investors still immediately recognize its true persistence.

Results with the recalibrated shock are shown in figure 6. Compared to the situation in which all agents have model-consistent expectations, the constraint posed by the zero lower bound under the standard Taylor rule is now somewhat less detrimental in the first few years following the shock. In part, this is because inflation is more inertial under VAR-based expectations, making the initial fall in inflation less severe and causing the Taylor rule without the zero bound imposed to prescribe less of an initial decline in the nominal funds rate. As a consequence, the initial decline in output under the constrained Taylor rule is only modestly more severe than the unconstrained version. After two years, however, output begins to recover more rapidly in the unconstrained case, as 
inflation begins to fall and the counterfactual interest rate is lower. On balance, as can be seen in line 1 of table 2, the zero bound boosts the ten-year loss by 75 percent, somewhat less than the comparative deterioration under full model-consistent expectations.

Figure 6 and table 2 also show that, under the alternative expectational assumptions, policies intended to mitigate the effects of the zero lower bound are, in many cases, substantially less effective than before. For example, the R-W rule with full makeup, despite keeping the nominal funds rate at zero for an additional one-and-a-half years, yields almost the same decline in output as produced under the constrained Taylor rule. Moreover, the ten-year loss is now 24 percent greater than that generated under the nozero-bound benchmark rule, instead of being 5 percent smaller. This deterioration in relative performance is exhibited by all the alternative policies except the preemptive Taylor-rule strategy. In some cases it is quite dramatic; for example, the loss under the mild change rule - which was only 35 percent of that generated under the benchmark rule when all expectations were model-consistent - now is more than twice the benchmark loss. And in the case of the aggressive change rule, performance deteriorates so sharply that the model is too unstable to solve - a result that Taylor (1999) noted occurred in models with adaptive expectations.

What accounts for this pronounced change in the relative performance of the rules? The main factor is that the promise of future policy actions beyond the zero-bound period no longer exerts as much influence on the longer-run inflation expectations of households and firms under VAR-based expectations. Financial market participants still know that these alternative policies will result in lower real short-term interest rates and higher inflation down the road relative to what occurs under the Taylor rule, and accordingly price these expectations into nominal bond yields immediately following the onset of the shock. However, because other agents do not recognize that the alternative monetary policies have significantly different implications for future inflation, their long-run inflation expectations are not greatly affected by any promised change in monetary policy. Thus, announcing a switch to the make-up rule or price-level targeting does not result in a jump in their inflation expectations relative to their expectations under the Taylor rule, and therefore does not result in a lower initial level of real bond rates relative to what happens under the Taylor rule. Given little difference in the initial level of real long-term interest rates as perceived by households and firms, outcomes for output and inflation turn out to be almost the same. 
As with the other policies, performance under price level targeting deteriorates sharply when households and firms base their expectations on the historical behavior of the economy: The losses in line 8 of table 2 are about three times greater than the corresponding losses in table 1 . Nonetheless, the strategy remains remarkably effective - its loss is only 13 percent higher than that generated under the unconstrained benchmark - despite relying on a promise that goes unrecognized by households and firms, that of persistently easier monetary policy in the future. This success is particularly surprising in light of its implications for real long-term interest rates. Financial markets, recognizing that the policy implies higher inflation and nominal shortterm interest rates down the road, set nominal bond rates at a level above that set under the Taylor rule (figure 6, middle-left panel). But households and firms, who do not understand that inflation will eventually be above baseline for a time as the price level is restored, interpret the higher level of nominal bond yields as higher real long-term rates - an event that, by itself, weakens real activity.

So why is price-level targeting still effective under these conditions? The answer lies in the policy's implications for the stock market and the foreign-exchange value of the dollar. As shown in figure 7, although price-level targeting implies higher real bond rates from the point of view of households and firms (top panel), investors correctly understand that it in fact implies a persistently lower level of real interest rates (middle panel). As a result, financial markets cause the real exchange rate to depreciate by more - a price change that supports real activity, relative to what occurs under the Taylor rule, by boosting exports and checking the demand for imports. The investor-perceived fall in real interest rates also raises equity prices by more than occurs under the Taylor rule, and so stimulates consumer spending through higher property wealth. Thus, even though price-level targeting pushes the perceived cost of borrowing in the wrong direction, it still works because wealth and exchange rate effects - which do not depend on households and firms having a correct understanding of future inflation developments — operate in the "correct" direction.

This dependence of price-level targeting on channels other than the cost of capital suggests a caveat about the simulation results. Our ability to account for historical movements in the exchange rate is extremely limited; perhaps the most uncertain link in the FRB/US monetary transmission mechanism is the response of the real exchange rate to changes in monetary policy. This uncertainty thus calls into question the likely effectiveness of price-level targeting in this case. Indeed, the relative advantage of the price-level targeting over the unconstrained benchmark rule deteriorates further if the 
recalibrated demand shock is re-simulated with the real exchange rate held constant. Admittedly, price-level targeting still outperforms the unconstrained Taylor rule in this case, but only because the policy is deemed completely credible by investors and so generates higher equity values.

These simulations suggest that the effectiveness of the expectations-based policies considered here depends on more than just communicating their implications to the bond market; households and firms need to understand the implications of a change in policy as well. While recent history suggests that financial market participants pay close attention to announced changes in monetary policy, it is less clear that other agents do so. Our analysis suggests that a central bank operating in a low inflation environment - in which the risk of hitting the zero bound is heightened - might want to consider discussing publicly how monetary policy will respond to a zero-bound episode well before such an event occurs.

Furthermore, this analysis reiterates our earlier point that, given the likelihood of gradual learning on the part of many agents, policies that can be implemented under normal conditions - such as a more-aggressive policy or a price-level target — may be preferable to policies such as the R-W rule that only come into play once the zero bound is hit.

\section{Fiscal policy under the zero bound}

Although the ability of conventional monetary policy to stabilize the economy is greatly diminished during zero-bound episodes, similar concerns do not apply to fiscal policy. In fact, there are even reasons to believe that the potency of fiscal policy should be enhanced at such times. To see this, note that an expansionary shift in fiscal policy, if sustained, raises the economy's equilibrium real interest rate. As a result, the enactment of a persistent increase in government spending or cut in taxes would be expected to boost both nominal and real long-term interest rates (all else equal) because investors foresee a higher future path for the real funds rate. This revision in financial conditions, in turn, limits the net stimulus from fiscal expansion. However, when short-term interest rates are pinned at zero, monetary policy may not turn more restrictive for a considerable time because nominal short-term rates are starting out higher than an unconstrained policy rule would prescribe. Put another way, unlike in the typical case, here, the central bank would welcome the additional stimulus generated by a looser fiscal policy. Understanding this, investors would then mark up their expectations for the future path of the funds rate by less than they would in the absence of the zero bound, resulting in a 
smaller rise in the bond rate and more net stimulus to aggregate demand from the fiscal policy action.

To illustrate these ideas, we now consider results from simulations in which fiscal policy offsets the aggregate demand shock to varying degrees. In the baseline, fiscal policy is modestly countercyclical. Specifically, real government spending on goods and services is held constant at its baseline path, while government transfer payments respond to changes in the cyclical state of the economy by the amount observed historically. Interest expense evolves endogenously in response to changes in interest rates and the outstanding stock of government debt. On the revenue side, effective tax rates respond to cyclical changes in economic activity to the degree observed historically, but are otherwise unchanged during the first fifteen years of the simulation. As a result, the government's budget deficit widens for a considerable time following the aggregate demand shock, increasing the stock of government debt relative to GDP by almost 12 percentage points after six years. Personal income tax rates adjust endogenously starting in the sixteenth year to push the government debt-to-GDP ratio gradually back to baseline - an assumption that serves to make fiscal policy a neutral factor in the long run.

We now consider a more aggressive fiscal response. Under this easier policy, the government enacts a major cut in personal income taxes in response to the economic slowdown. Because of delays in the legislative process, the tax cut is assumed to begin one year after the aggregate demand shock first hits the economy; however, in the prior year all agents correctly anticipate the legislation's enactment. The tax cut amounts to 1 percent of GDP as computed on an ex ante basis and lasts for five years. Although the easy fiscal policy yields a larger medium-term rise in the debt-to-GDP ratio (of 15 percentage points), all agents understand that tax rates will be adjusted beginning in the sixteenth year to return the ratio to baseline gradually.

Simulation results under the alternative fiscal policies are shown in figure 8; all results are generated using the standard Taylor rule and full model-consistent expectations. As expected, the easier fiscal policy shortens the duration of the zero-bound episode and shifts up the subsequent path of the federal funds rate, thereby reducing the initial fall in the nominal bond rate that follows the onset of the aggregate demand shock (the dashed line). However, because long-run inflation expectations rise by a corresponding amount, the change in the real bond rate is about the same under the baseline and easier fiscal policies during the first few years. Thus, the greater stimulus provided by the tax cuts of 
the easier fiscal policy is not appreciably offset by higher real interest rates, and the fall in aggregate output is smaller.

The situation is quite different in the case of a fiscal expansion that takes place when the zero bound is not a factor. If the easier policy is implemented in the absence of the large demand shock (dotted line, figure 8), it yields almost no change in either the output gap or inflation because real bond rates are free to jump following enactment of the tax cut. A similar result is obtained if the effects of the large demand shock and changes in fiscal policy are simulated without imposing the zero bound constraint; under such conditions, fiscal policy has again little affect on output or prices. This "crowding-out" property of the FRB/US model is discussed at length in Elmendorf and Reifschneider (2002).

Three lessons from these simulations seem clear. First, even if the central bank's ability to stabilize the economy is constrained by the zero lower bound on nominal interest rates, fiscal policy can still be used to stimulate real activity and limit any undesirable declines in inflation. Second, the effectiveness of fiscal policy as a stabilization tool is probably enhanced by the zero lower bound, not diminished. Third, tightening the stance of fiscal policy during a zero-bound episode is potentially quite destabilizing because of asymmetries in inflation and output dynamics under such conditions.

\section{Conclusions}

The simulations we have presented suggest that a central bank has a number of options that can significantly mitigate the consequences of the zero bound on nominal interest rates for the severity of recessions. Policy changes that were particularly effective include a more-aggressive inflation-targeting policy; a monetary policy that promises to make up any shortfall in interest rates induced by the zero bound; and a policy of price-

level targeting. However, the efficacy of these policies depends on firms and households forming inflation expectations in a manner that is fully consistent with these policies. We find that it is not enough for financial markets to understand the implications of these policies for future monetary policy; it is also important for households and firms to understand their implications for future policy, and thus for future inflation.

Our results are thus more sanguine for general changes in policy that are put in place under normal conditions than for special changes made only after the zero bound is reached. In particular, our results suggest that a central bank that wishes to operate with a low inflation target as a general matter might also wish to make other accompanying 
changes to policy — such as adopting a more-aggressive policy or moving to a price-level target - to allow more time for their stabilizing implications to become fully incorporated into expectations. In addition, a central bank that shifts to a low inflation target - and thereby increases the risk of hitting the zero bound at a future date - might do well to expedite the learning process by making clear in advance what its policies would be in the event of a zero-bound episode.

A central bank that finds itself already confronted with the zero bound must rely to a greater extent on persuasion so as to influence the inflation expectations of households and firms. A strategy of talking up inflation expectations - within the context of one of the general strategies we have discussed-would be important. Nonetheless, our results also suggested that announcing a permanent change in the inflation target is neither necessary nor particularly effective, at least in the context of the FRB/US model. Rather, announcing that policy will be looser than usual for a sustained (but not infinite) period would be sufficient. 
Table 1

Cost of the Zero Lower Bound (ZLB) and Relative Macroeconomic Performance in the Face of the Large Demand Shock Under Alternative Monetary Policies When All Agents Have Model-Consistent Expectations

\begin{tabular}{|c|c|c|c|c|}
\hline & \multicolumn{3}{|c|}{ Loss (L) } & \multirow[b]{2}{*}{$\begin{array}{c}\text { Relative } \\
\text { Performance }^{\dagger}\end{array}$} \\
\hline & $\begin{array}{c}\text { With } \\
\text { ZLB } \\
\text { Imposed }\end{array}$ & $\begin{array}{l}\text { Without } \\
\text { ZLB } \\
\text { Imposed }\end{array}$ & $\begin{array}{c}\text { Cost of } \\
\text { the } \\
\mathrm{ZLB}^{\S}\end{array}$ & \\
\hline 1. Taylor rule & 365.0 & 188.3 & .94 & 1.94 \\
\hline 2. Aggressive Taylor rule (inflation only) & 160.4 & 70.4 & 1.28 & .85 \\
\hline 3. Aggressive Taylor rule (inflation/output) & 132.8 & 45.3 & 1.93 & .71 \\
\hline 4. R-W rule with full makeup & 178.6 & 188.3 & -.05 & .95 \\
\hline 5. R-W rule with partial makeup & 295.8 & 188.3 & .57 & 1.57 \\
\hline 6. Taylor rule with $1 \%$ point hike in $\pi^{*}$ & 344.4 & 234.8 & .47 & 1.83 \\
\hline 7. Taylor rule with preemptive response & 369.7 & 185.7 & .99 & 1.96 \\
\hline 8. Price level targeting & 100.8 & 98.8 & .02 & .54 \\
\hline 9. Aggressive change rule & 17.2 & 15.9 & .08 & .09 \\
\hline 10. Mild change rule & 66.0 & 65.8 & .003 & .35 \\
\hline
\end{tabular}

${ }^{\S}$ Change in loss under the specified policy created by imposing the zero lower bound, divided by the loss generated under the policy without the constraint imposed.

${ }^{\dagger}$ Loss under the specified policy with the zero lower bound imposed, divided by the loss generated under the standard Taylor rule without the zero lower bound imposed. 
Table 2

Cost of the Zero Lower Bound (ZLB) and Relative Macroeconomic Performance in the Face of the Recalibrated Demand Shock Under Alternative Monetary Policies When Only Financial Market Participants Have Model-Consistent Expectations

\begin{tabular}{|c|c|c|c|c|}
\hline & \multicolumn{3}{|c|}{ Loss (L) } & \multirow[b]{2}{*}{$\begin{array}{c}\text { Relative } \\
\text { Performance }\end{array}$} \\
\hline & $\begin{array}{c}\text { With } \\
\text { ZLB } \\
\text { Imposed }\end{array}$ & $\begin{array}{l}\text { Without } \\
\text { ZLB } \\
\text { Imposed }\end{array}$ & $\begin{array}{c}\text { Cost of } \\
\text { the } \\
\text { ZLB }^{\S}\end{array}$ & \\
\hline 1. Taylor rule & 458.3 & 261.7 & .75 & 1.75 \\
\hline 2. Aggressive Taylor rule (inflation only) & 310.5 & 155.4 & 1.00 & 1.19 \\
\hline 3. Aggressive Taylor rule (inflation/output) & 288.9 & 87.2 & 2.31 & 1.10 \\
\hline 4. R-W rule with full makeup & 325.6 & 261.7 & .24 & 1.24 \\
\hline 5. $\mathrm{R}-\mathrm{W}$ rule with partial makeup & 416.9 & 261.7 & .59 & 1.59 \\
\hline 6. Taylor rule with $1 \%$ point hike in $\pi^{*}$ & 535.9 & 326.3 & .64 & 2.05 \\
\hline 7. Taylor rule with preemptive response & 393.9 & 240.6 & .64 & 1.51 \\
\hline 8. Price level targeting & 295.6 & 239.3 & .24 & 1.13 \\
\hline 9. Aggressive change rule & $\mathrm{NC}$ & $\mathrm{NC}$ & $\mathrm{NC}$ & $\mathrm{NC}$ \\
\hline 10. Mild change rule & 592.0 & 567.3 & .04 & 2.26 \\
\hline
\end{tabular}

${ }^{\S}$ Change in loss under the specified policy created by imposing the zero lower bound, divided by the loss generated under the policy without the constraint imposed.

${ }^{\dagger}$ Loss under the specified policy rule with the zero lower bound imposed divided by the loss hypothetically achievable under the standard Taylor rule without the zero lower bound imposed.

$\mathrm{NC}$ - not computable. 


\section{Figure 1 \\ Macroeconomic Effects of the Large Demand Shock Under Taylor Rules with Alternative Degrees of Aggressiveness}

Federal Funds Rate

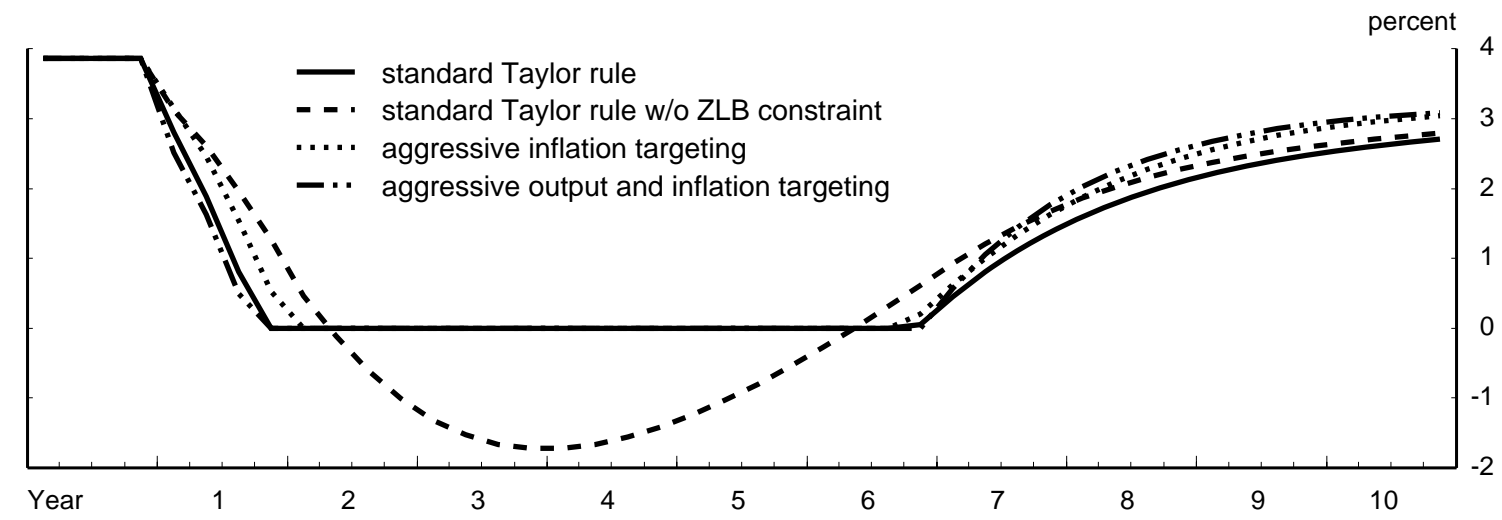

10-Year Treasury Yield

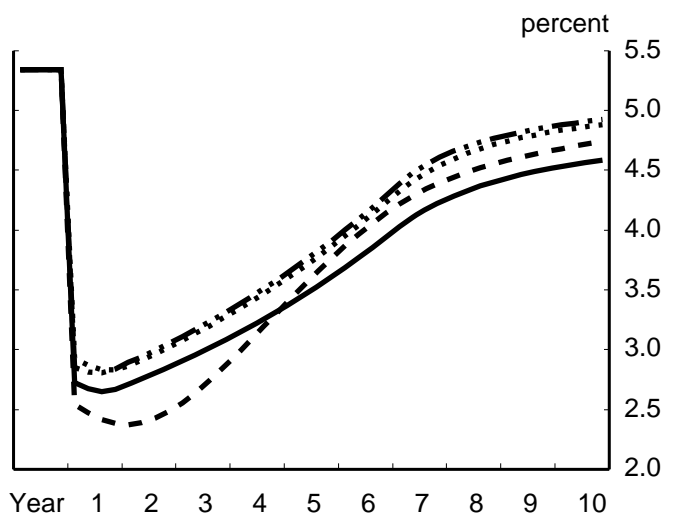

Output Gap

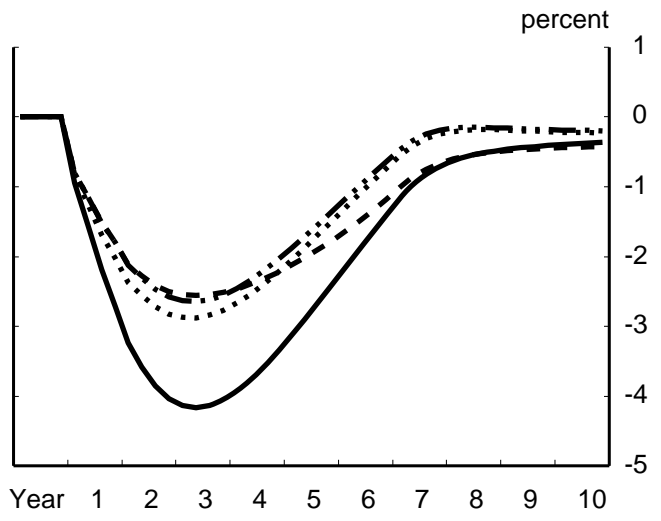

Real Expected Bond Yield

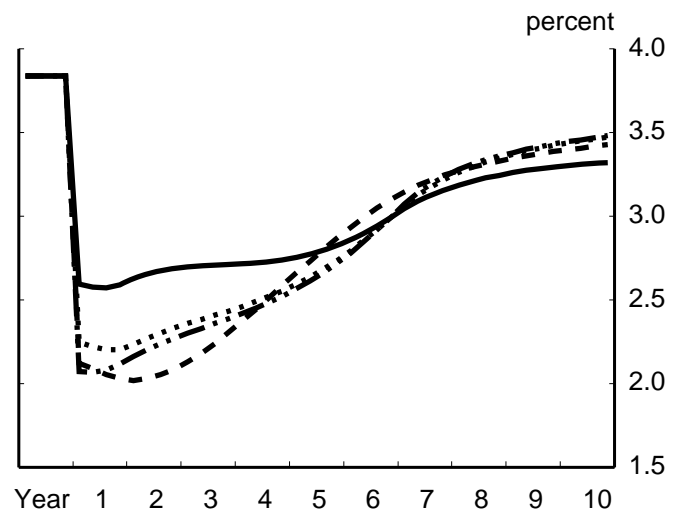

Consumer Inflation (4-qtr)

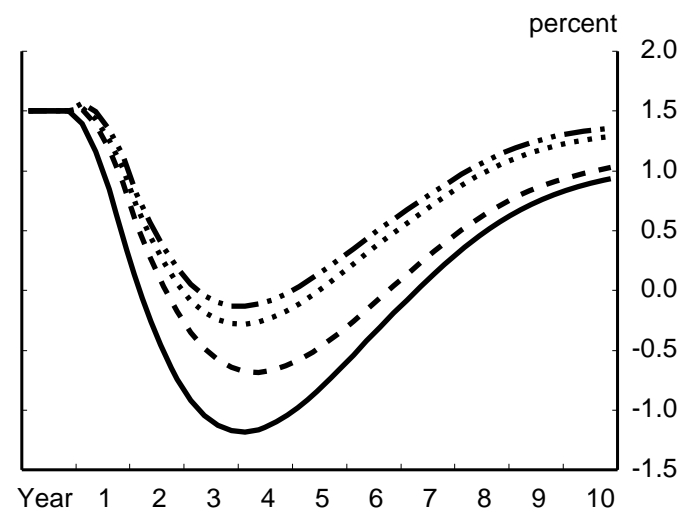


Figure 2

Macroeconomic Effects of the Large Demand Shock Under the R-W Rule, With and Without Full Makeup of Past Funds Rate Shortfalls

Federal Funds Rate

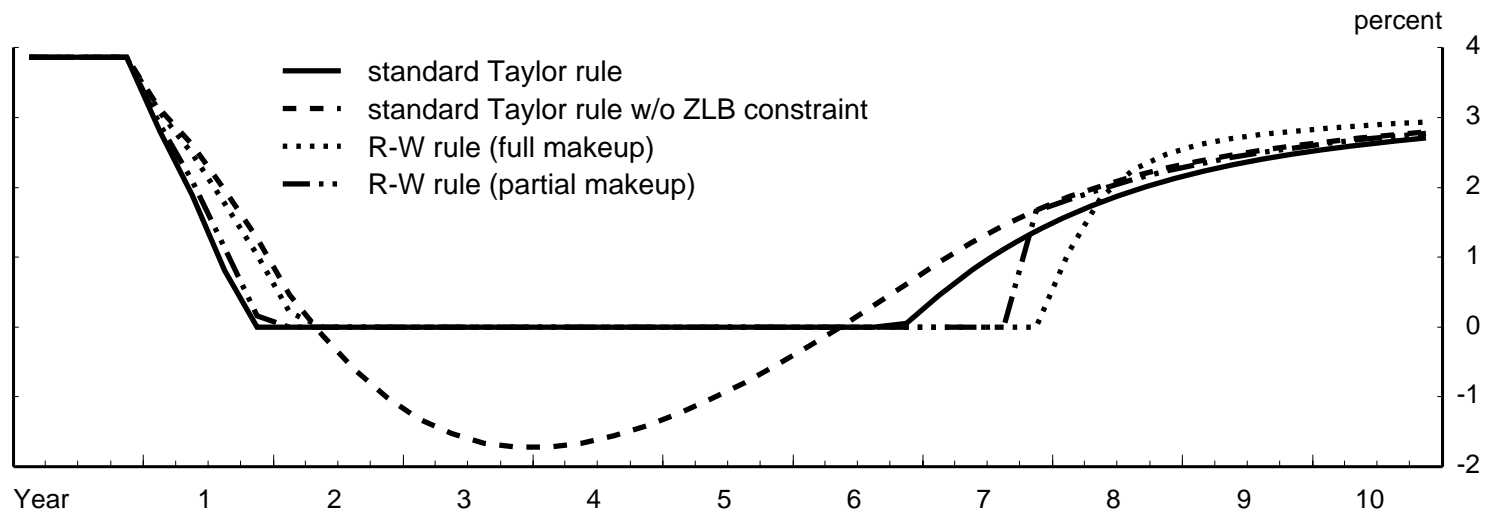

10-Year Treasury Yield

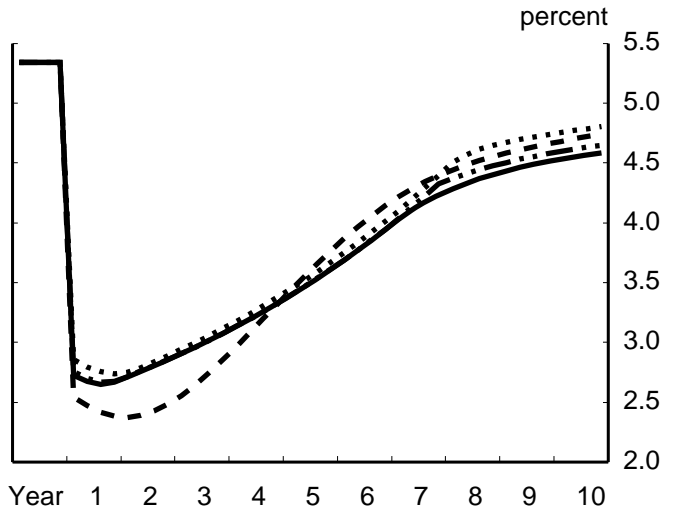

Output Gap

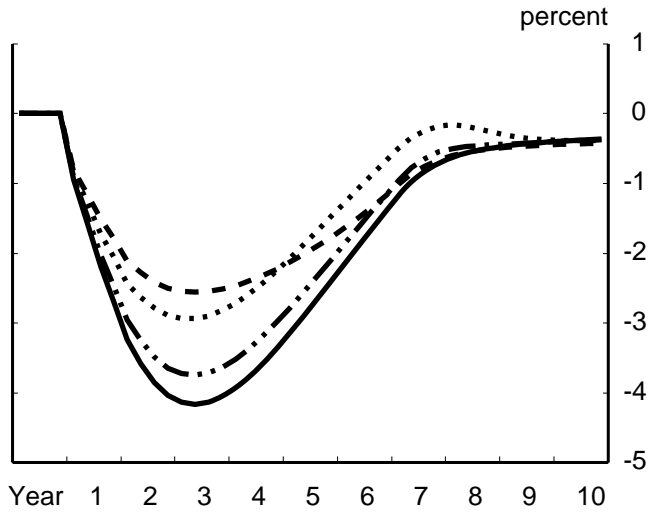

Real Expected Bond Yield

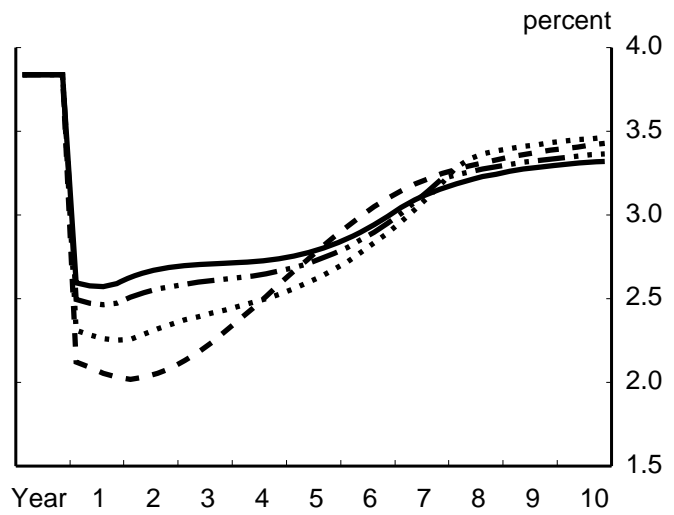

Consumer Inflation (4-qtr)

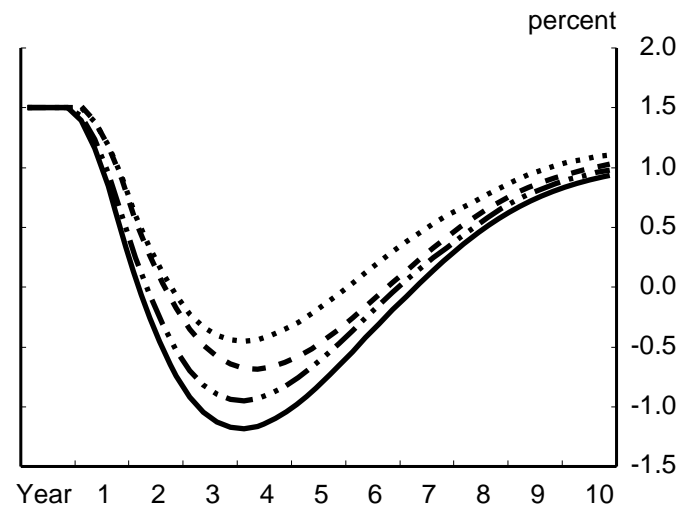


Figure 3

Macroeconomic Effects of the Large Demand Shock

\section{Under the Taylor Rule with Either a Preemptive Policy Response or an Announced 1\% Point Increase in the Inflation Target}

Federal Funds Rate

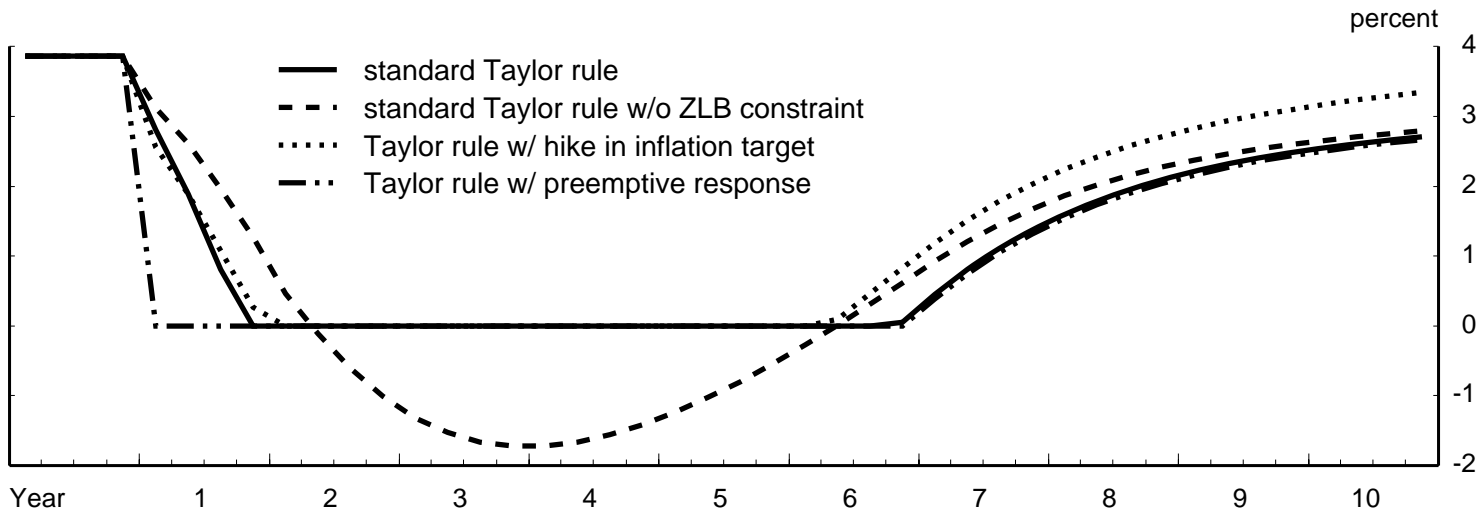

10-Year Treasury Yield

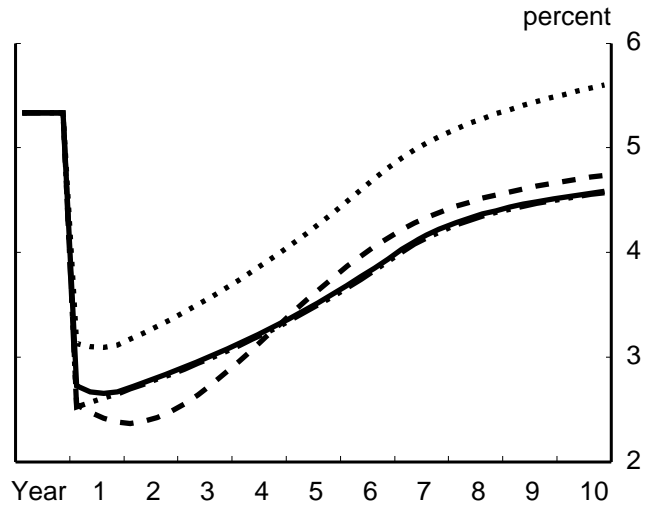

Output Gap

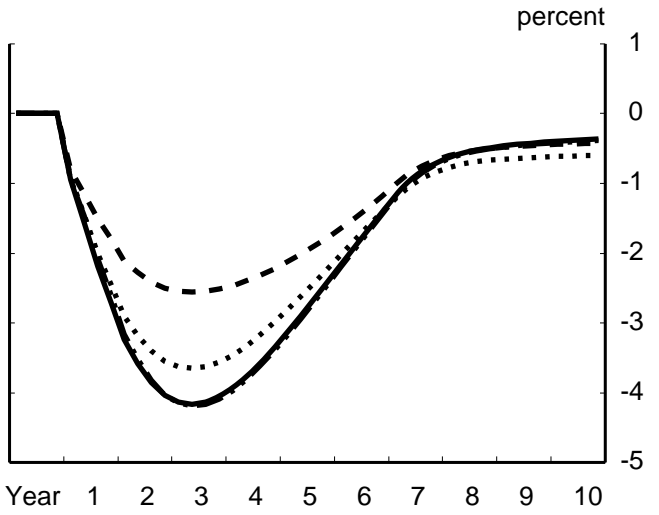

Real Expected Bond Yield

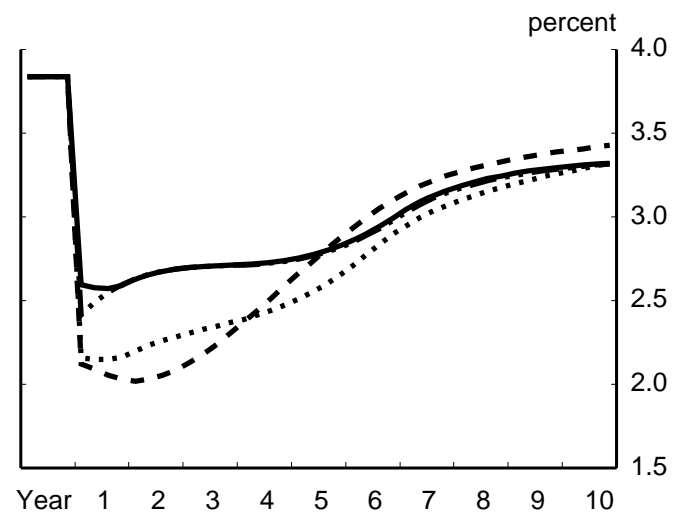

Consumer Inflation (4-qtr)

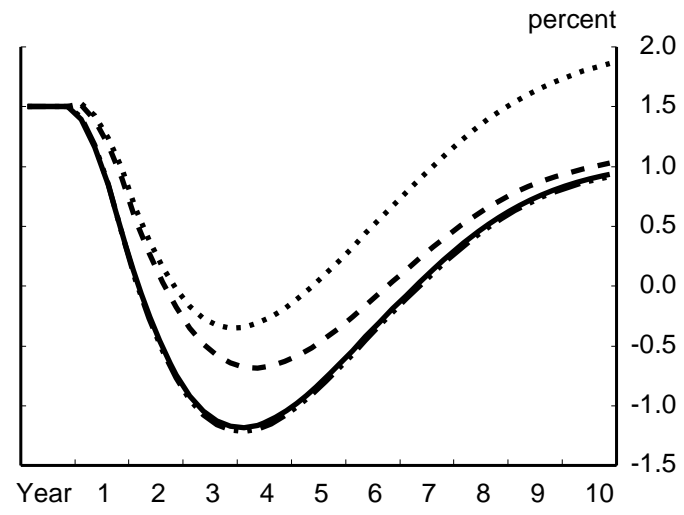


Figure 4

\section{Macroeconomic Effects of the Large Demand Shock} Under Price Level Targeting and the Change Rule

Federal Funds Rate

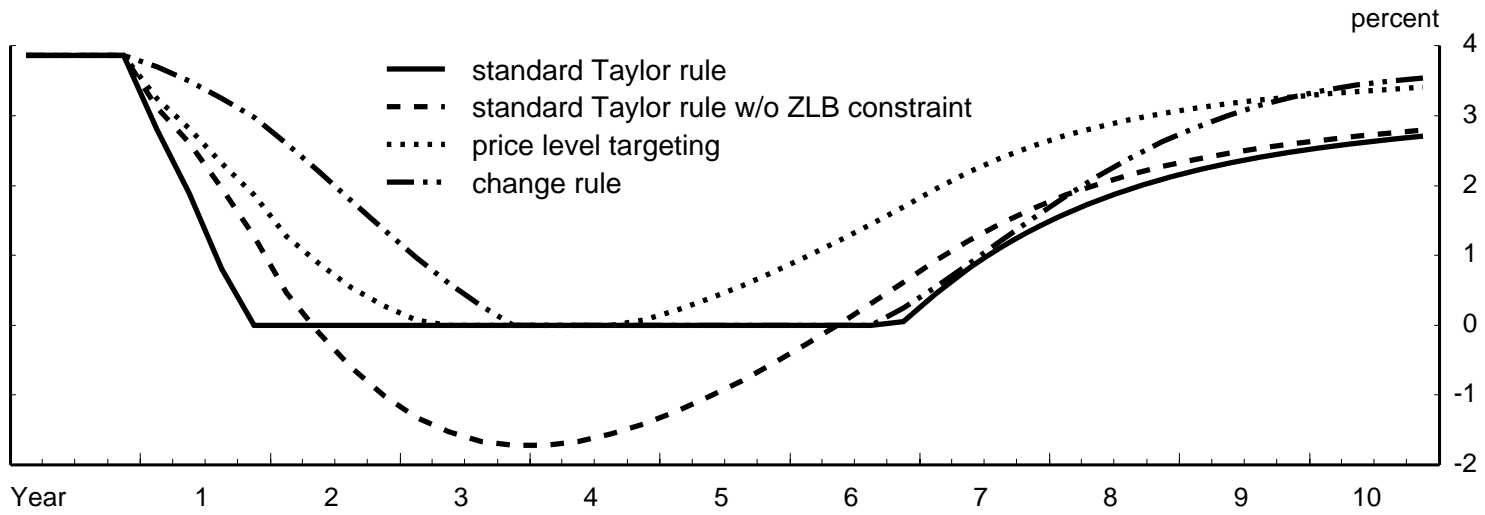

10-Year Treasury Yield

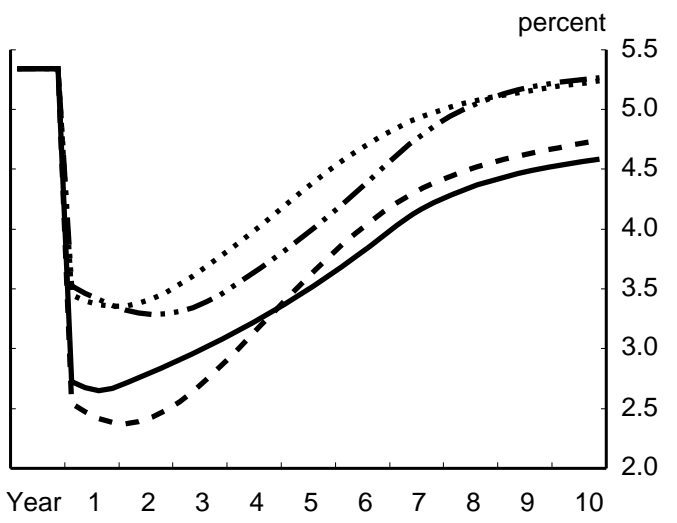

Output Gap

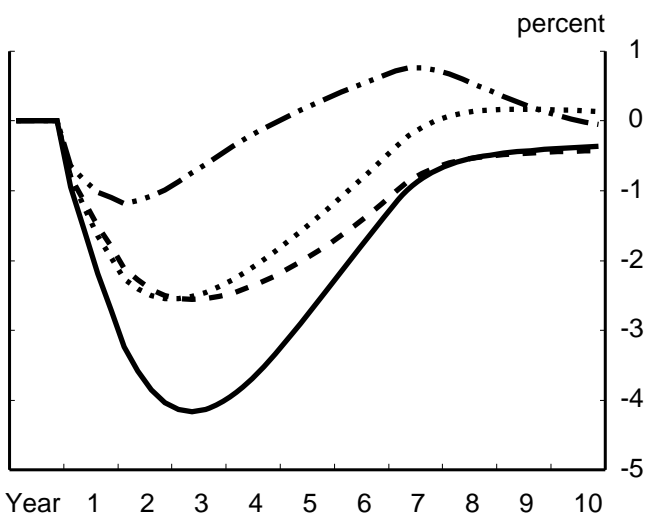

Real Expected Bond Yield

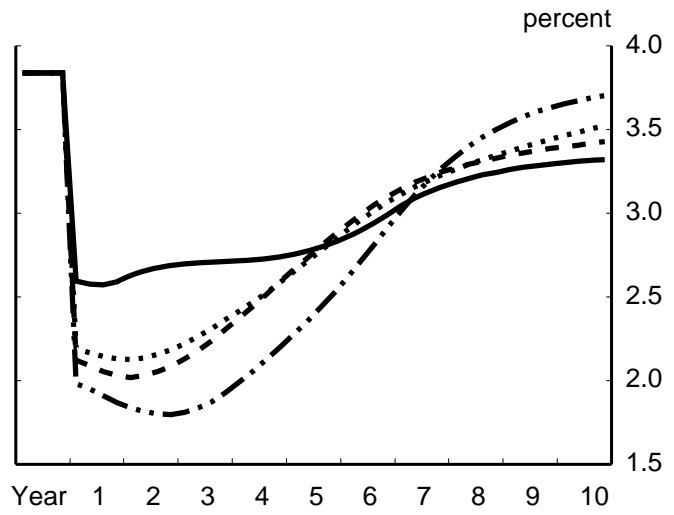

Consumer Inflation (4-qtr)

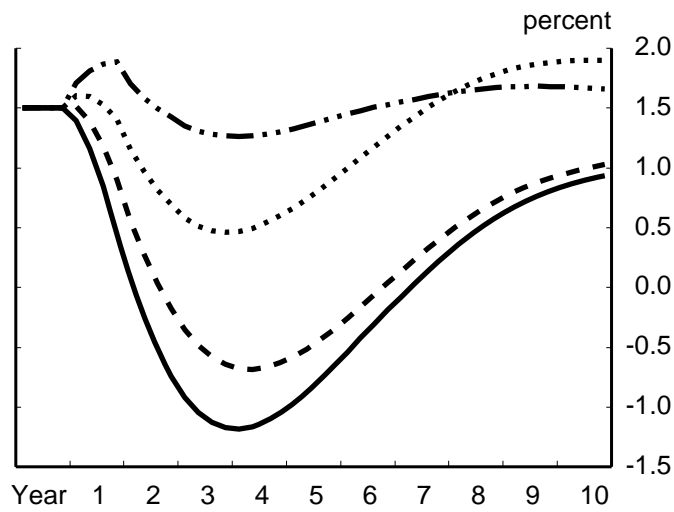


Figure 5

Implications of the Financial Sector Alone Having Model-Consistent Expectations for the Effect of the Large Demand Shock Under the Taylor Rule

Federal Funds Rate

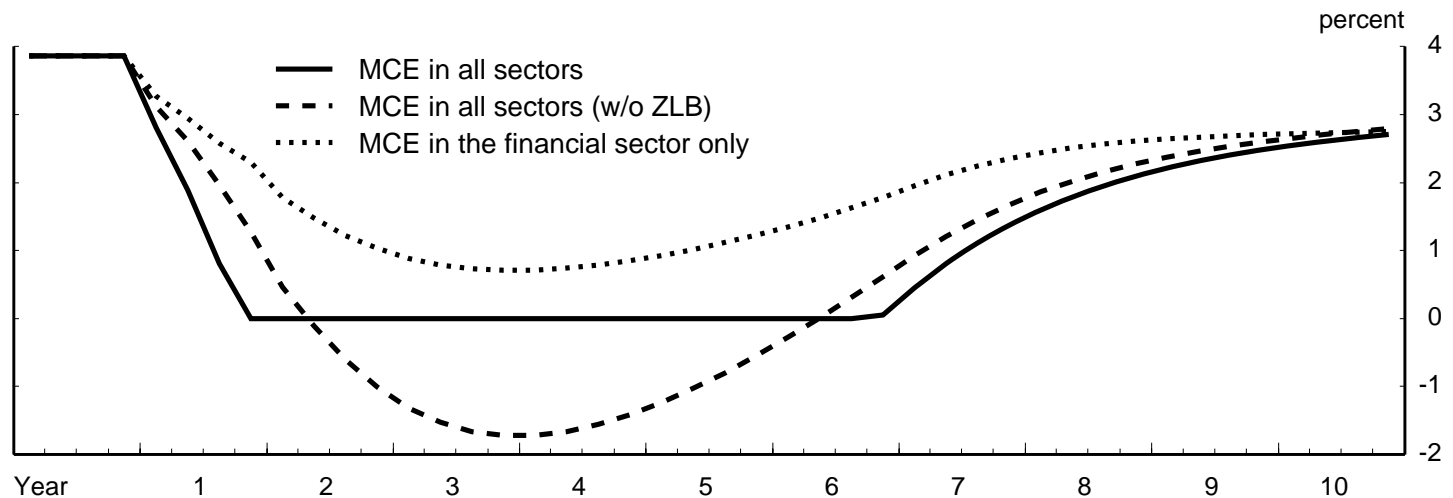

10-Year Treasury Yield

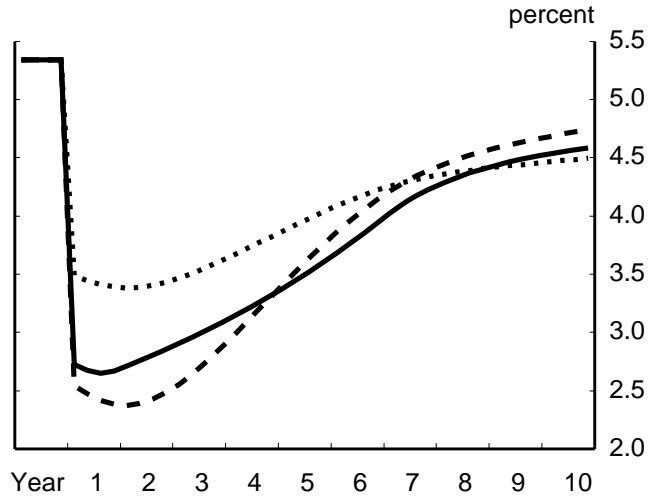

Output Gap

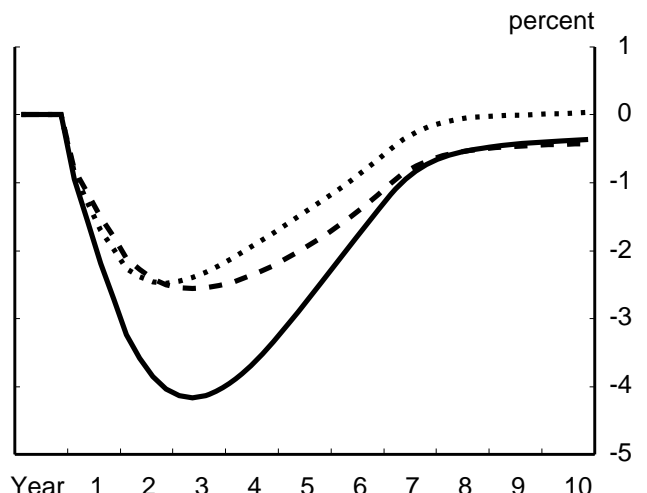

Real Expected Bond Yield

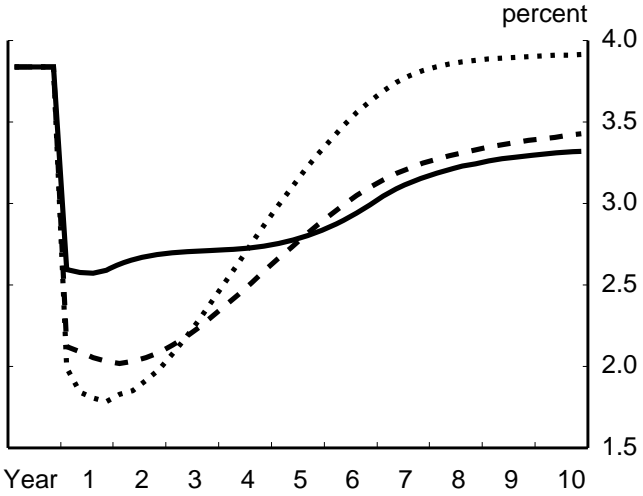

Consumer Inflation (4-qtr)

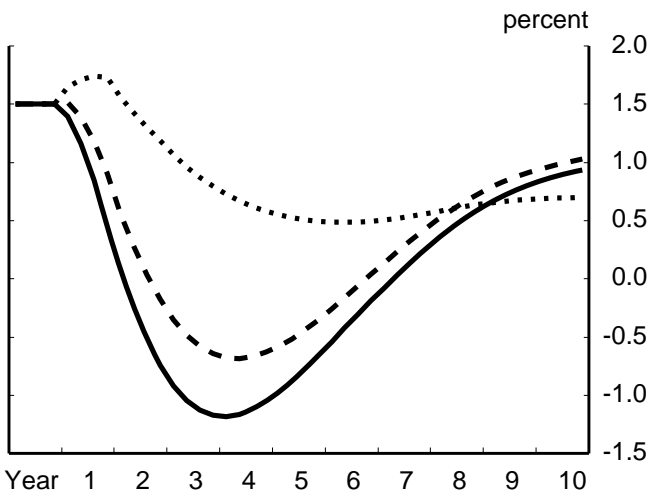


Figure 6

Macroeconomic Effects of the Recalibrated Demand Shock

Under the Taylor Rule, R-W Rule, and Inflation Targeting

When Financial Market Expecations Alone are Model-Consistent

Federal Funds Rate

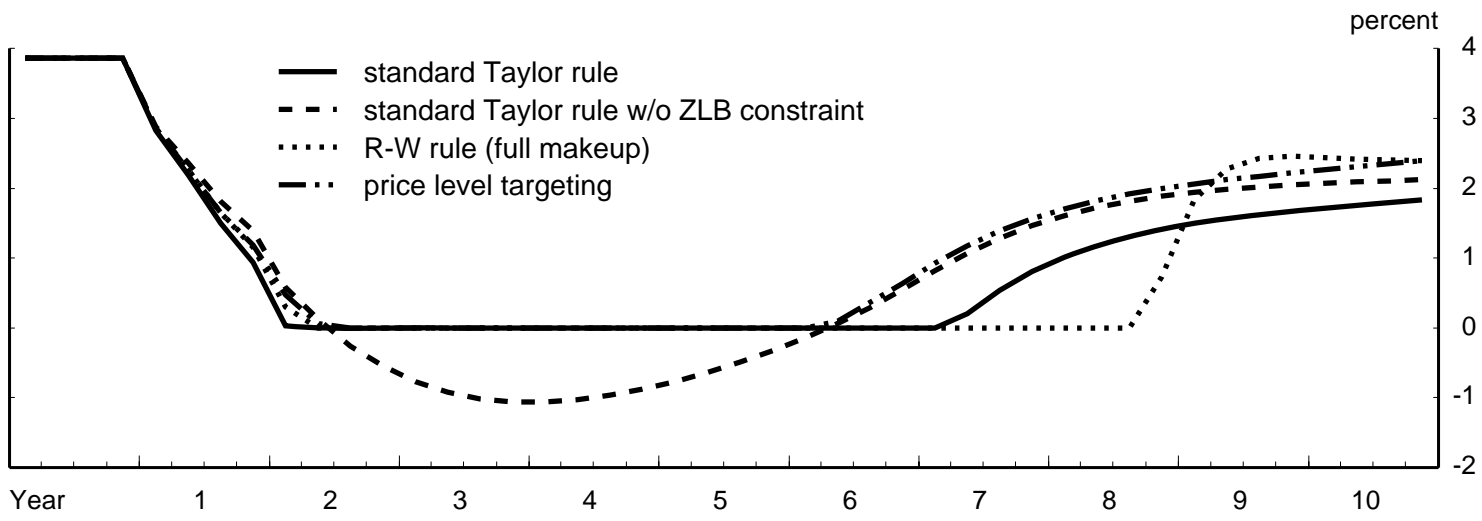

10-Year Treasury Yield

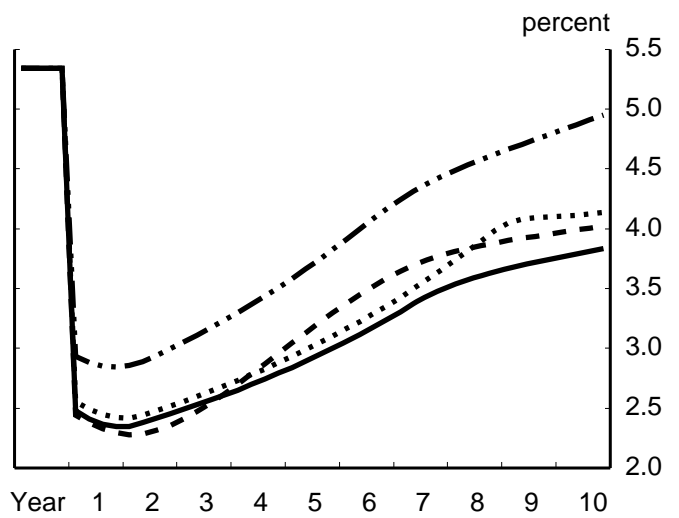

Output Gap

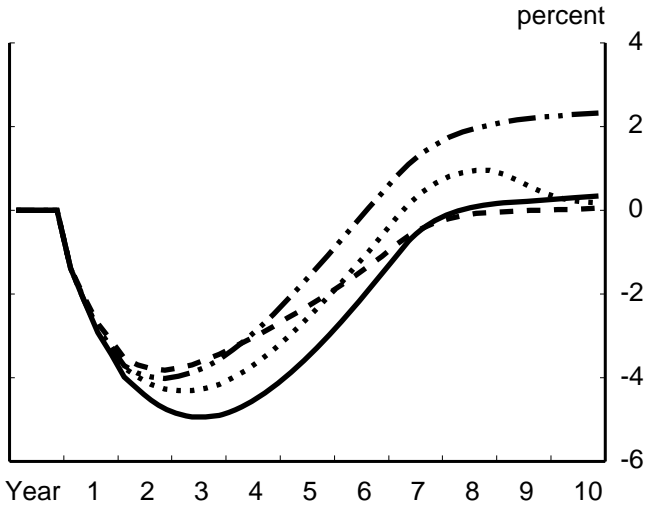

Real Expected Bond Yield

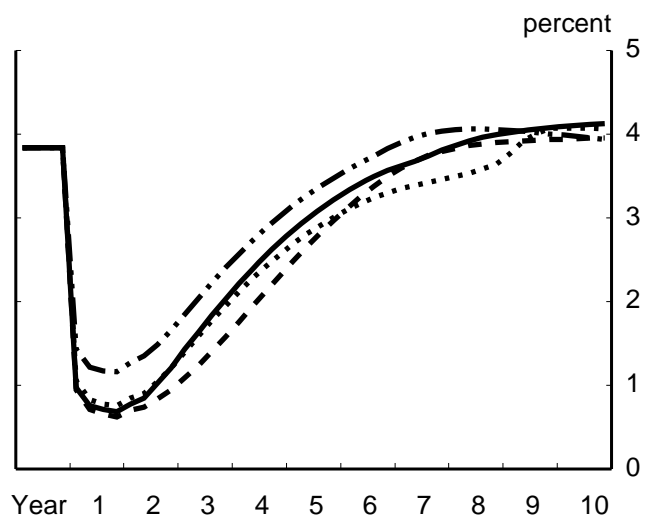

Consumer Inflation (4-qtr)

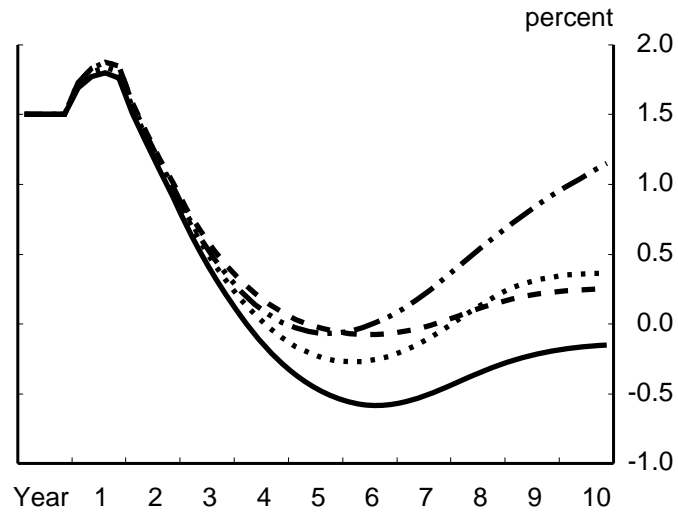


Figure 7

Foreign Trade Implications of Long-Run Inflation Expectations

that Differ Between Financial Market Participants and Other Agents

Under Alternative Policy Reponses to the Recalibrated Demand Shock (financial market expectations alone are model consistent)

Real Bond Yield (View of HHs and Firms)

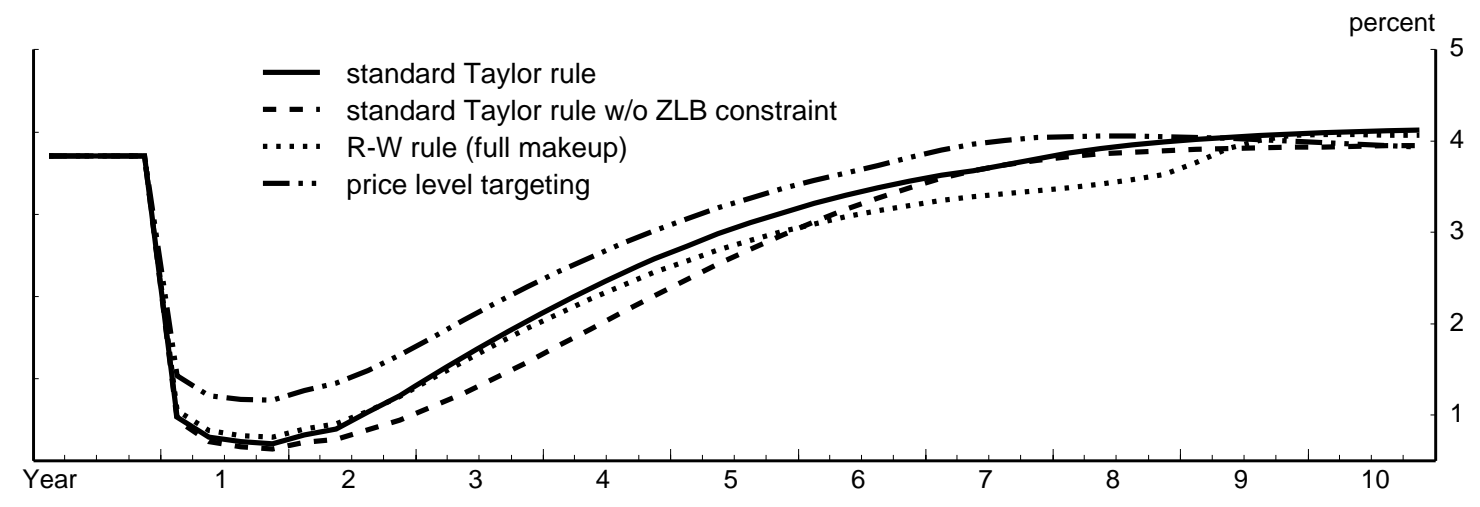

Real Bond Yield (View of Investors)

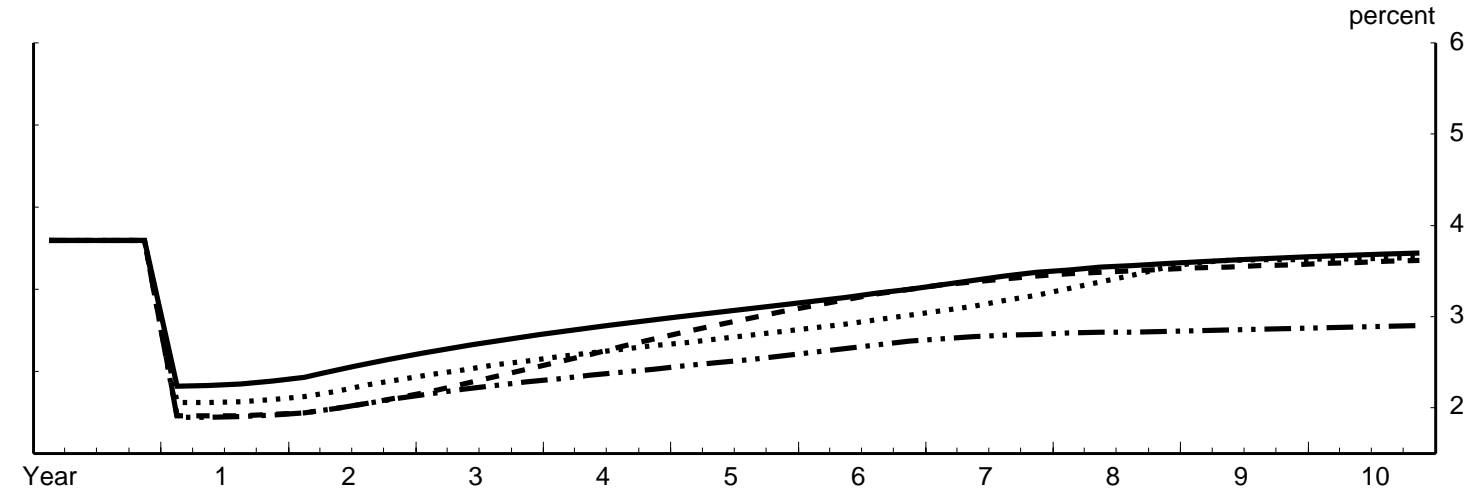

Real Exchange Rate

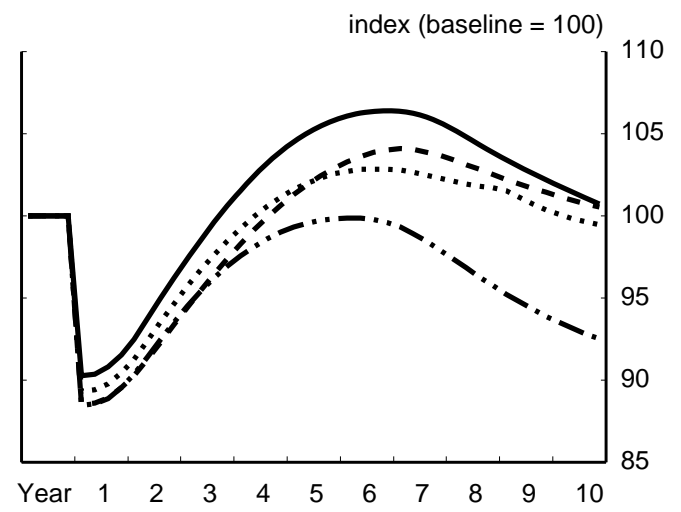

Real Exports

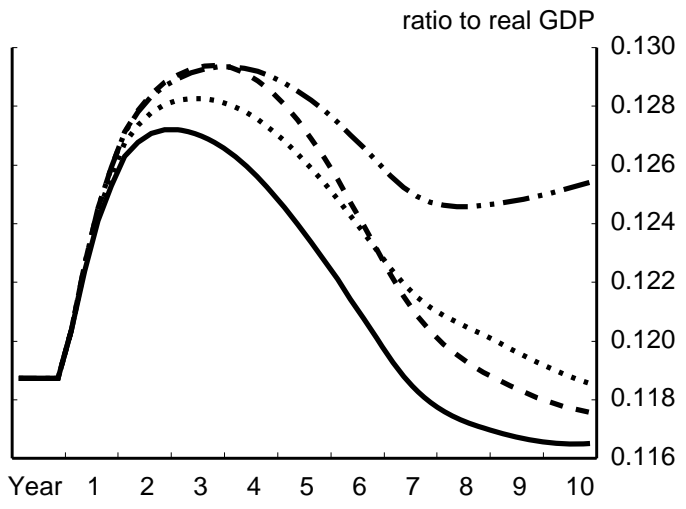


Figure 8

Implications of the Zero Bound for the Effectiveness of Fiscal Policy Under the Taylor Rule and Full Model-Consistent Expectations

Federal Funds Rate

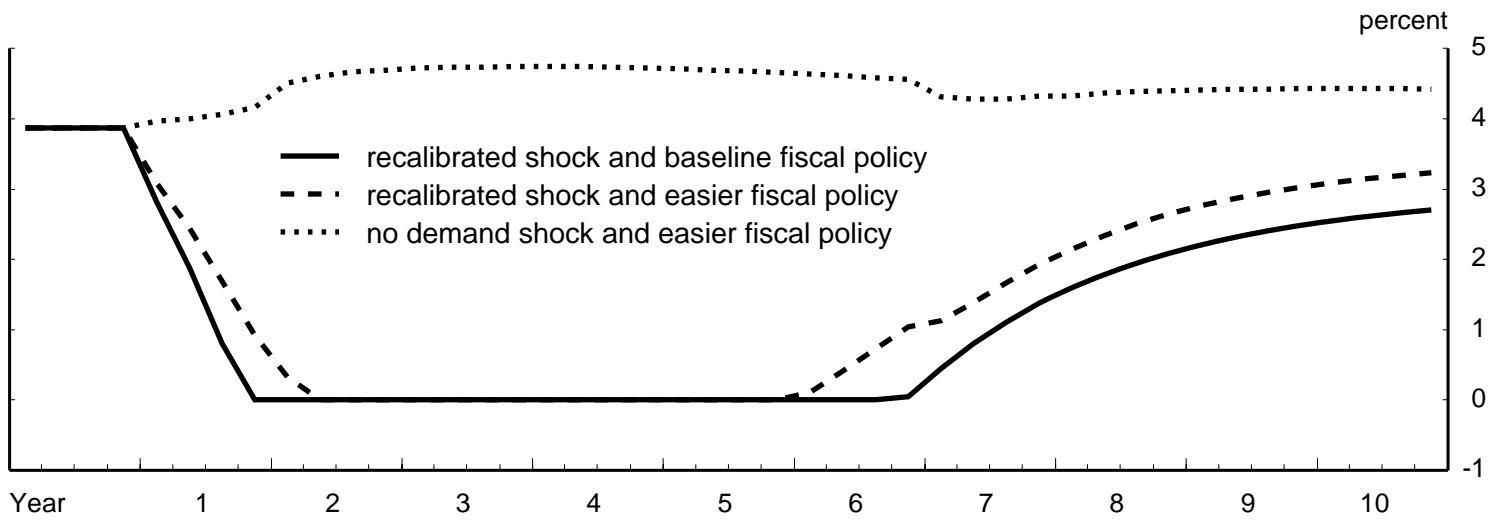

10-Year Treasury Yield

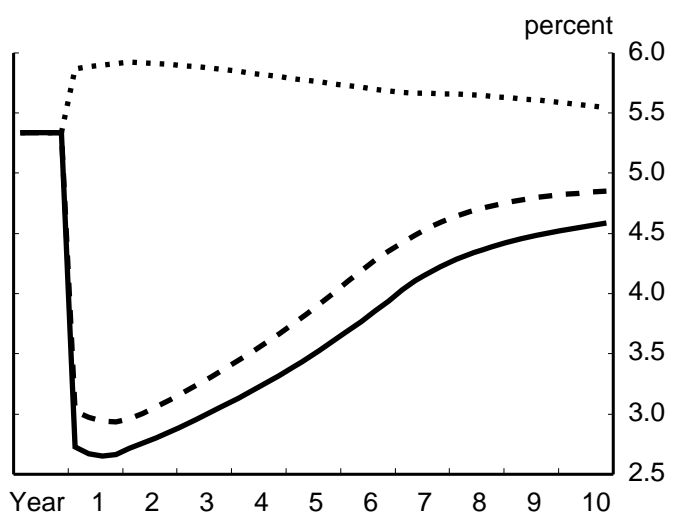

Output Gap

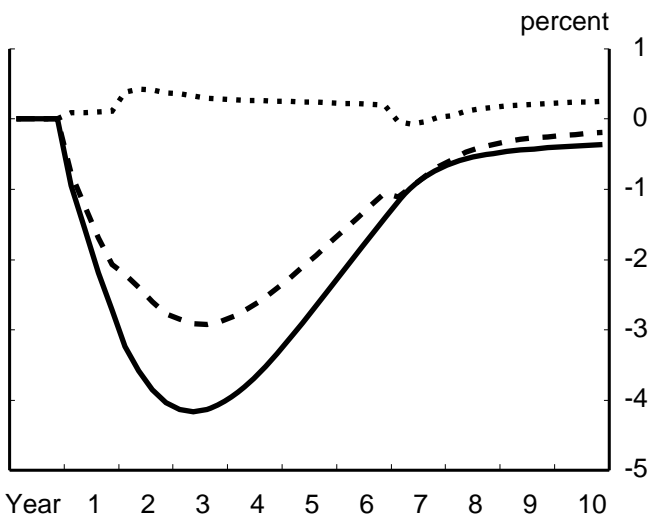

Real Expected Bond Yield

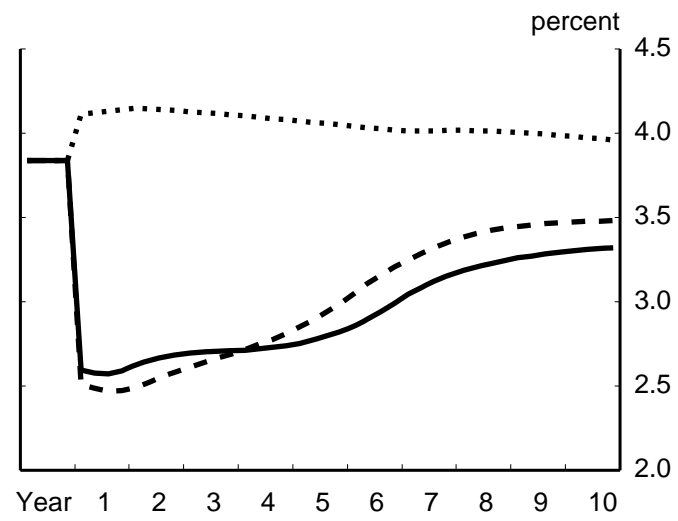

Consumer Inflation (4-qtr)

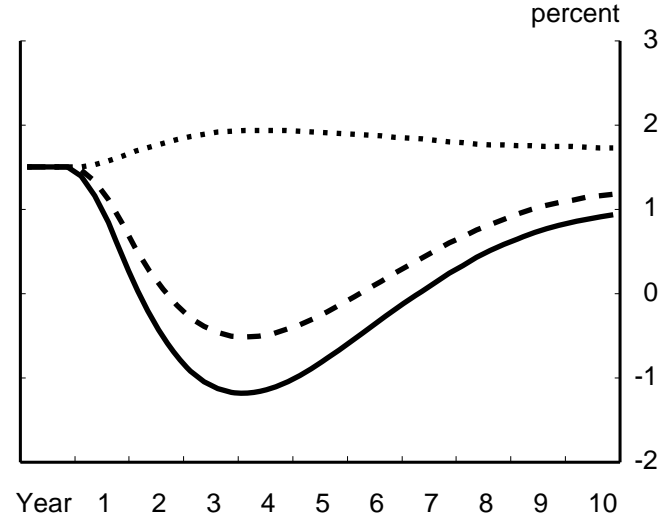




\section{References}

Bernanke, Ben S., Vincent R. Reinhart, and Brian P. Sack (2004) "Monetary Policy Alternatives at the Zero Bound: An Empirical Assessment," Brookings Papers on Economic Activity 2004:1, 1-78.

Boivin, Jean and Marc P. Giannoni (2003) "Has Monetary Policy Become More Effective?" NBER working paper no. 9459. Also, forthcoming, Review of Economics and Statistics.

Brayton, Flint, and Peter Tinsley (1996) "A Guide to FRB/US: A Macroeconomic Model of the United States," Federal Reserve Board FEDS working paper no. 1996-42.

, Andrew Levin, Ralph Tryon, and John C. Williams (1997) "The Evolution of Macro Models at the Federal Reserve Board." Carnegie-Rochester Conference Series on Public Policy 47, 43-81.

, Eileen Mauskopf, David Reifschneider, Peter Tinsley, and John Williams (1997) "The Role of Expectations in the FRB/US Macroeconomic Model." Federal Reserve Bulletin 83, 227-45.

Clarida, Richard, Jordi Gali, and Mark Gertler (2000) "Monetary Policy Rule and Macroeconomic Stability: Evidence and Some Theory." Quarterly Journal of Economics 115, 147-80.

Clouse, James, Dale Henderson, Athanasios Orphanides, David Small, and Peter Tinsley (2000) "Monetary Policy When the Short-Term Interest Rate is Zero." Federal Reserve Board FEDS working paper no. 2000-51 (November).

Coenen, Gunther, Athanasios Orphanides, and Volker Wieland (2004) "Price Stability and Monetary Effectiveness when Nominal Interest Rates are Bounded at Zero." Advances in Macroeconomics 4.

Eggertson, Gauti B., and Michael Woodford (2003) "The Zero Bound on Interest Rates and Optimal Monetary Policy." Brookings Papers on Economic Activity 2003:1, 139-234.

Elmendorf, Douglas, and David L. Reifschneider (2002) "Short-Run Effects of Fiscal Policy with Forward-Looking Financial Markets.” National Tax Journal 55, 357-86.

English, William B., William R. Nelson, and Brian P. Sack (2003) "Interpreting the Significance of Lagged Interest Rates in Estimated Monetary Policy Rules," Contributions to Macroeconomics 3.

Erceg, Christopher J., and Andrew T. Levin (2003) "Imperfect Credibility and Inflation Persistence," Journal of Monetary Economics 50, 915-44. 
Henderson, Dale, and Warwick J. McKibbin (1993) "A Comparison of Some Basic Monetary Policy Regimes for Open Economies: Implications of Different Degrees of Instrument Adjustment and Wage Persistence." Carnegie-Rochester Conference Series on Public Policy 39, 221-318.

Gürkaynak, Refet S., Brian Sack, and Eric Swanson (2005) "The Sensitivity of LongTerm Interest Rates to Economic News: Evidence and Implications for Macroeconomic Models," American Economic Review 95, 425-36.

Kohn, Donald L. and Brian P. Sack (2003) "Central Bank Talk: Does It Matter and Why?" Federal Reserve Board FEDS working paper no. 2003-55.

Krugman, Paul R. (1998) "It's Baaack: Japan's Slump and the Return of the Liquidity Trap." Brookings Papers on Economic Activity 1998:2, 137-206.

Levin, Andrew, Volker Wieland, and John C. Williams (1999) "Robustness of Simple Monetary Policy Rules under Model Uncertainty." In Monetary Policy Rules, John B. Taylor, ed. University of Chicago Press. , and (2003) "The Performance of Forecast-Based Monetary Policy Rules under Model Uncertainty." American Economic Review 93, 622-45.

Orphanides, Athanasios, and John C. Williams (2002) "Robust Monetary Policy Rules with Unknown Natural Rates." Brookings Papers on Economic Activity 2002:2, 63-145.

Reifschneider, David L., Robert J. Tetlow, and John C. Williams (1999) "Aggregate Disturbances, Monetary Policy, and the Macroeconomy: The FRB/US Perspective." Federal Reserve Bulletin 85, 1-19. , and John C. Williams (2000) "Three Lessons for Monetary Policy in a LowInflation Era." Journal of Money, Credit, and Banking 32, 936-78.

Reinhart, Vincent R. (2004) "Rendering the Zero Bound on Nominal Interest Rates Irrelevant." Board of Governors of the Federal Reserve System, photocopy.

Roberts, John M. (2004) “Monetary Policy and Inflation Dynamics," Federal Reserve Board FEDS working paper no. 2004-62 (October).

Svensson, Lars E.O. (1999) "Price-Level Targeting versus Inflation Targeting: A Free Lunch?" Journal of Money, Credit, and Banking 31, 277-95. (2000) "How Should Monetary Policy Be Conducted in an Era of Price Stability?" NBER Working Paper Series, No. 7516. 
Taylor, John B. (1999) “Introduction.” In Monetary Policy Rules, John B. Taylor, ed. University of Chicago Press.

Wolman, Alexander L. (2005) "Real Implications of the Zero Bound on Nominal Interest Rates." Journal of Money, Credit, and Banking 37, 273-96.

Yates, Tony (2002) "Monetary Policy and the Zero Bound to Interest Rates: A Review" European Central Bank Working Paper No. 190. 